\title{
Effects of assimilating precipitation zones derived from satellite and lightning data on numerical simulations of tropical-like Mediterranean storms
}

\author{
L. Fita, R. Romero, A. Luque, and C. Ramis \\ Grup de Meteorologia, Departament de Física, Universitat de les Illes Balears, Palma de Mallorca, Spain \\ Received: 4 March 2008 - Revised: 15 May 2009 - Accepted: 29 July 2009 - Published: 26 August 2009
}

\begin{abstract}
The scarcity of meteorological observations in maritime areas is a well-known problem that can be an important limitation in the study of different phenomena. Tropical-like storms or medicanes developed over the Mediterranean sea are intense storms with some similarities to the tropical ones. Although they do not reach the hurricane intensity, their potential for damage is very high, due to the densely populated Mediterranean coastal regions. In this study, the two notable cases of medicane development which occurred in the western Mediterranean basin in September 1996 and October 2003, are considered. The capability of mesoscale numerical models to simulate general aspects of such a phenomena has been previously shown. With the aim of improving the numerical results, an adjustment of the humidity vertical profiles in MM5 simulations is performed by means of satellite derived precipitation. Convective and stratiform precipitation types obtained from satellite images are used to individually adjust the profiles. Lightning hits are employed to identify convective grid points. The adjustment of the vertical humidity profiles is carried out in the European Centre for Medium-Range Weather Forecasts (ECMWF) analyses used as initial conditions for the simulations. Analyses nudging to ECMWF analyses and to the satellite-based humidity-corrected version of these analyses has also been applied using Four Dimensional Data Assimilation (FDDA). An additional adjustment is applied as observation nudging of satellite/lightning information at different time and spatial resolutions. Statistical parameters are proposed and tested as an objective way to intercompare satellite-derived and simulated trajectories. Simulations of medicanes exhibit a strong sensitivity to vertical humidity profiles. Trajectories of the storms are improved or worsened by using FDDA. A case dependence is obtained on the
\end{abstract}

Correspondence to: L. Fita

(lluis.fita@uib.cat) characteristics of the humidity-corrected medicanes. FDDA sensitivity on temporal and spatial resolution of the assimilated data also presents a case dependence. It also shows a significant sensitivity of the results of the observation nudging to the specific choice of the values of coefficient weight and vertical ratio of the ingested observations.

Keywords. Meteorology and atmospheric dynamics (Lightning; Mesoscale meteorology; Instruments and techniques)

\section{Introduction}

Mediterranean tropical-like storms, Mediterranean Polar Lows or Medicanes (Medi-terranean+Hurri-canes) have been studied in different ways: observationally (Rasmussen and Zick, 1987; Businger and Reed, 1989), numerical simulations with limited area models (Lagouvardos et al., 1999; Pytharoulis et al., 2000; Reed et al., 2001; Homar et al., 2003) and with an axi-symmetric hurricane numerical model (Emanuel, 2005; Fita et al., 2007). These studies describe medicanes as quasi-symmetric organised convective systems with a low pressure centre and a warm core. They are observed in satellite pictures as rounded cloud structures and some of them even develop a cloud free centre like a hurricane "eye". They are associated with strong winds and heavy precipitation.

It has been observed that their development occurs within preexisting unstable conditions that can present high convective activity. In some cases, medicanes are formed as a secondary low derived from a wider cyclone. They have a maritime origin and they vanish when they reach the coast. Mediterranean tropical-like storms are associated with an upper-level cold low which, together with the warm and moist air in contact with the sea, establishes the necessary conditions for the medicane formation (Emanuel, 2005). Their development shares some similarities with tropical

Published by Copernicus Publications on behalf of the European Geosciences Union. 

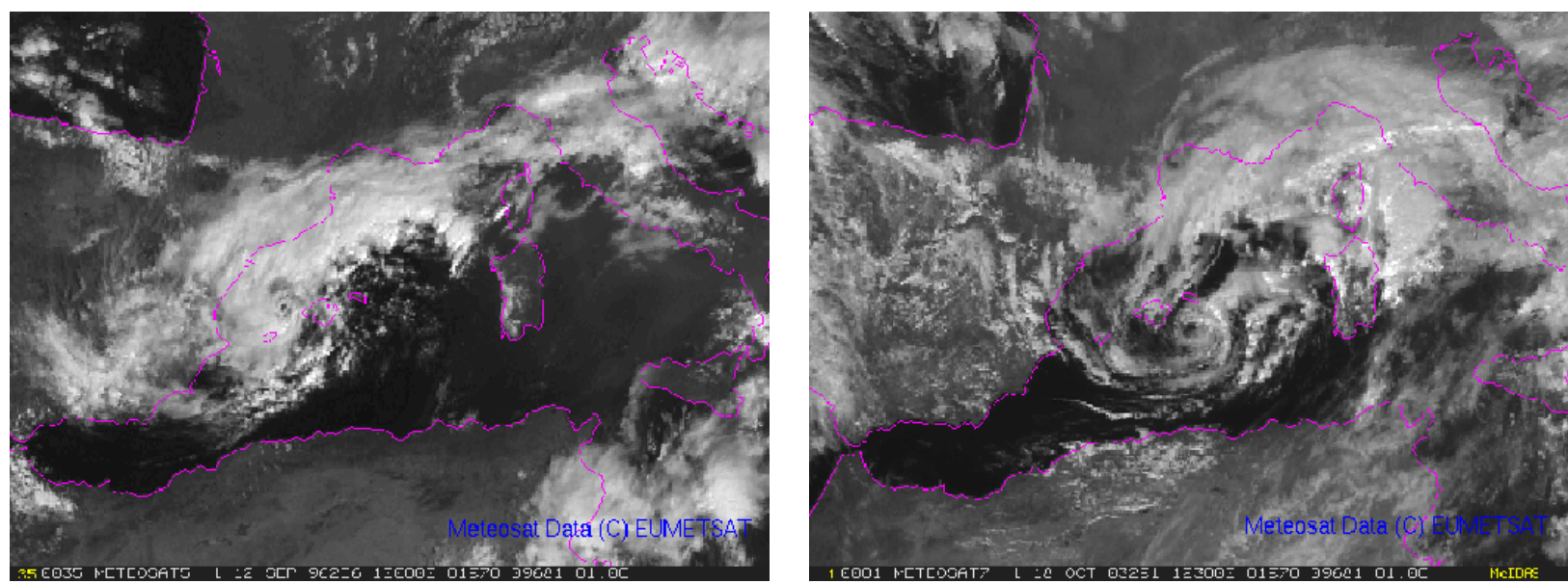

Fig. 1. Mature state of 960912 medicane on 12 September 1996 at 13:00 UTC (METEOSAT-5, left) and 031018 medicane on 18 October 2003 at 12:30 UTC (METEOSAT-7, right). Source METEOSAT Eumetsat.

disturbances due to the role of the air-sea interaction mechanism (Emanuel, 1986). Tropical-like behaviour, modulated by the interaction with an upper-level disturbance, has similarities with the dynamics of Polar Lows (Rasmussen and Zick, 1987; Montgomery and Farrell, 1992).

Limited area mesoscale numerical models have shown a reasonable ability in simulating these storms (Lagouvardos et al., 1999; Pytharoulis et al., 2000; Reed et al., 2001; Homar et al., 2003), in spite of the limited observational data given by their maritime origin. Reed et al. (2001) show the sensitivity and beneficial effects on the numerical simulation when sea surface temperatures are corrected with observations.

The modification of numerical simulations using observations from different sources has been shown as a successful way to improve the results. Some examples are given below; Stauffer and Seaman (1990) assimilate rawisonde data to correct the mass and wind fields and improve atmospheric dynamics and precipitation. Leslie et al. (1998) use satellitederived winds in order to improve a hurricane track. Zou and Xiao (1999) obtain better hurricane characteristics by introducing bogus data. Fan and Tilley (2002) use satelliteretrieved humidity and vertical and horizontal cloud distribution and forecast better precipitation. Ducrocq et al. (2002) assimilate a large amount of observations like radar reflectivities, surface observations and Meteosat data at the initial fields and improve the forecasted precipitation. Davolio and Buzzi (2004) saturate model grid-points with observed rainy information and improve atmospheric dynamics and precipitation. Orlandi et al. (2004) assimilate rainfall rates and obtain better forecasted precipitation. Lagouvardos and Kotroni (2005) assimilate satellite derived precipitation and improve medium and high precipitation amounts.

MM5 model (Grell et al., 1995) uses a four-dimensional data assimilation (FDDA) tool based on a Newtonianrelaxation or nudging (Stauffer and Seaman, 1990) applied on the prognostic equations. The aim of this paper is a possible method for the improvement of medicane simulations using satellite-derived information. Improved simulations, detection and knowledge of the medicanes is crucial in order to mitigate their potential destructiveness on the densely populated Mediterranean coastal territories. Satellite-derived precipitation type (stratiform or convective) is used to modify humidity vertical profiles through FDDA in MM5 simulations. Lightning activity is used to mark convective points. The technique is applied to the simulation of the September 1996 case (studied by Homar et al., 2003) and October 2003 (studied by Fita et al., 2007).

Section 2 of the paper contains a short description of the two medicane cases, followed by a section devoted to the methodology. Discussion of the results is provided in Sect. 4 and the study ends with the conclusions and some ideas for further work.

\section{Selected cases}

September 1996 (960912) medicane developed in the Western Mediterranean basin within an intense convective zone located between the Iberian peninsula and the Balearic Islands (see Fig. 1). After a period of organisation and intensification, it moved eastward and an intense and rapid pressure fall as well as strong winds were measured at Palma de Mallorca (see Homar et al., 2003, for more details).

The October 2003 (031018) case also developed in the Western Mediterranean basin. A weak vortex, initiated to the south of the Iberian peninsula, evolved along the eastern coast of Spain until it reached an area with thunderstorm activity located between the Iberian peninsula and the Balearic Islands. Later, convective cloud cluster acquired a cyclonic rotation and formed the medicane (the reader is referred to a 


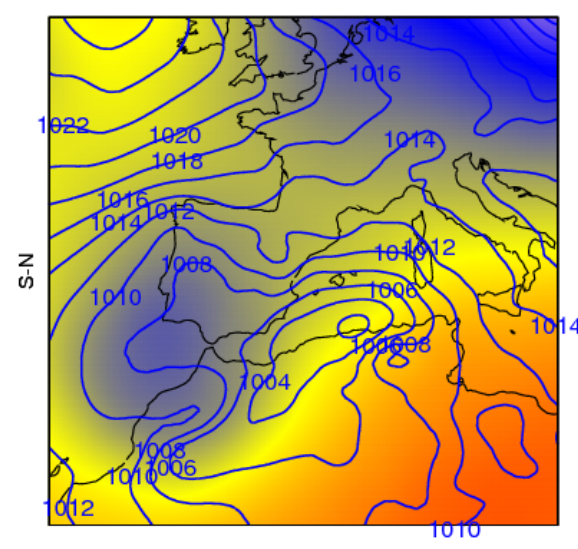

W-E

$\mathrm{T}$ at $850 \mathrm{hPa}\left({ }^{\circ} \mathrm{C}\right)$

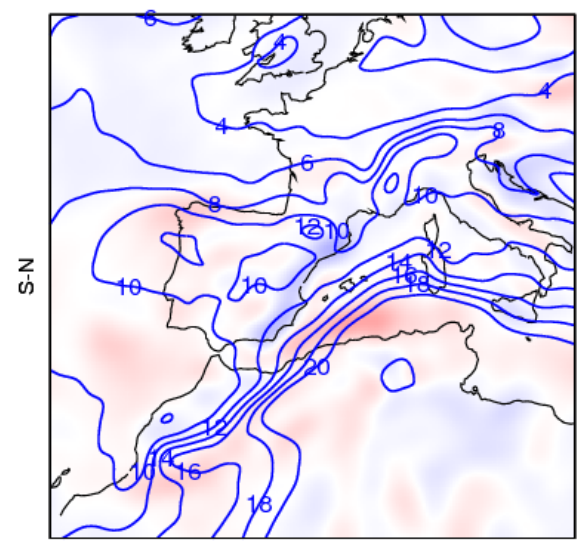

W-E

ErPV Is $330 \mathrm{~K}$ (PVU)
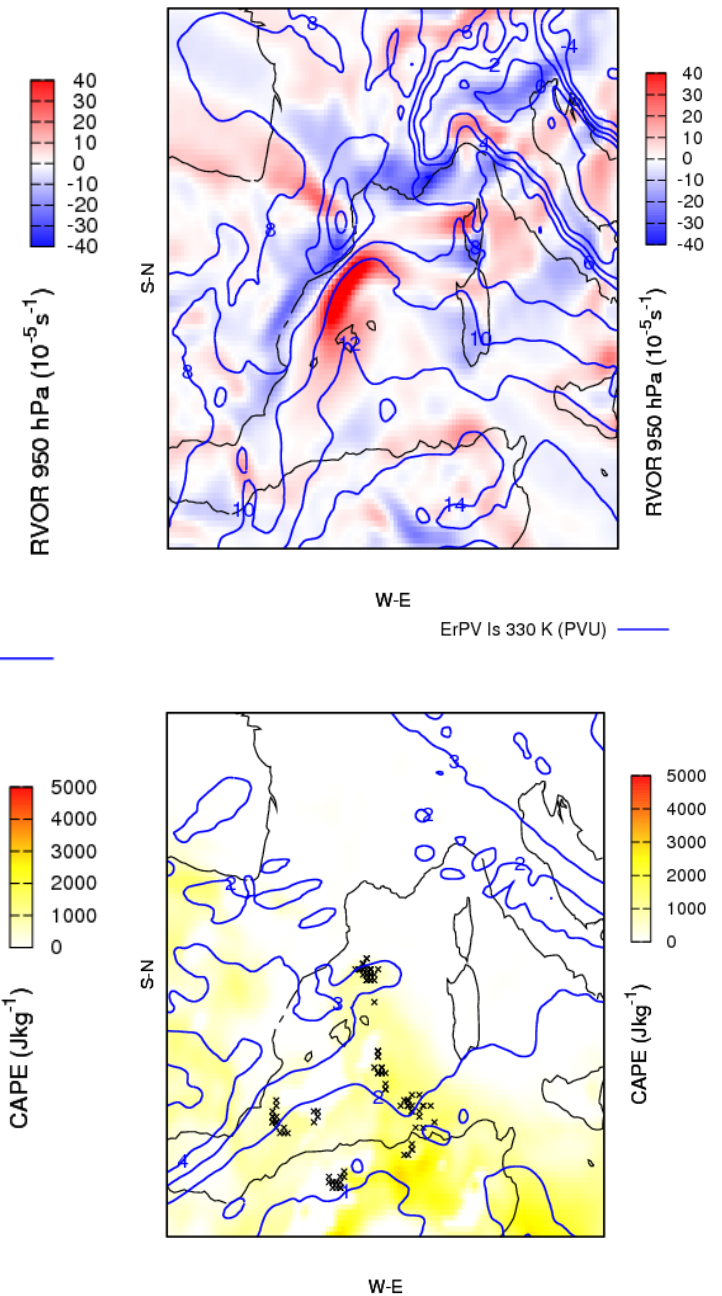

Fig. 2. ECMWF synoptic analyses on 11 September 1996 at 12:00 UTC (left) and 17 October 2003 at 00:00 UTC (right). Top panels: Sea level pressure (contours) and Geopotential Height at $500 \mathrm{hPa}$ (colour shaded). Middle panels: Temperature at $850 \mathrm{hPa}$ (contours) and Relative vorticity at $950 \mathrm{hPa}$ (colour shaded). Bottom panels: Ertel PV on $330 \mathrm{~K}$ Isentropic surface (contours) and CAPE (colour shaded), black crosses indicate lightning hit at given dates, except for October 2003 in which the hits correspond to 17 October 2003 at 00:30 UTC. 
web page ${ }^{1}$ with satellite movies of these two cases and other events).

Synoptic environments for the two cases present similar characteristics. An upper-level trough was located over the Iberian peninsula. At the same time, a significant lowlevel horizontal thermal gradient was present in the zone (see Fig. 2). Meanwhile, thunderstorms within a convectively unstable environment were present over maritime areas.

The MM5 version 3.7 mesoscale model has been used to simulate these two cases. Two domains in two-way interaction with a horizontal resolution of 15 and $5 \mathrm{~km}$ with 23 vertical levels, have been defined. The domains have different dimensions and are centred at different points for each case. Initial and boundary conditions are derived from the European Center for Medium-range Weather Forecasts (ECMWF) global analyses (at 00:00, 06:00, 12:00, and 18:00 UTC with a spatial resolution; $\mathrm{T} 213,0.5625^{\circ}$ degrees, for September 1996 case, and T511, 0.351 ${ }^{\circ}$ degrees, for October 2003 episode). Analyses have been improved with Binary Universal Form for data Representation (BUFR) observations (radiosonde and surface reports) archived at ECMWF (in FM-94 BUFR format, see WMO, 2007). ECMWF analyses are mixed with BUFR data with an objective analyses. By this way, higher resolution features are resolved in the coarse resolution of ECMWF analyses. The main MM5 physical configuration is graupel(reisner2) for moist microphysical scheme, Kain-Fritsch cumulus scheme activated in both domains and cloud scheme for radiation (Grell et al., 1995). As planetary boundary layer representation, it has been chosen as the ETA scheme (Janjić, 1990, 1994).

\section{Methodology}

\subsection{Assimilation of precipitation zones}

Satellite data from European Organisation for the Exploitation of Meteorological Satellites (EUMETSAT) and lightning datasets provided by Agencia Estatal de Meteorología (AEMET, Spanish Met. Office) show deep convection (observed as cold cloud top pixels) and lightning activity during the formation phase of both storms (Luque et al., 2007). During their mature state, the number of cold cloud top pixels decreased, as well as lightning activity (mostly located at this stage in warm cloud top pixels; not shown).

Infrared $(11 \mu \mathrm{m})$ satellite images are used to depict stratiform or convective precipitation type according to the method described below. Lightning discharges (only cloudground hits) are used to assist in the delineation of convective areas, assuming that all lightning activity is developed within convective cells. Once the precipitation type is obtained for each pixel, the MM5 humidity vertical profile is modified according to two different vertical structures including a

\footnotetext{
${ }^{1}$ http://www.uib.es/depart/dfs/meteorologia/ METEOROLOGIA/MEDICANES/
}

layer of saturated air (stratiform or convective structure, see Fig. 3).

The Histogram Matching Technique (HMT) is used to derive rain characteristics (intensity of precipitation for a given cloud top infrared temperature value) from the satellite images (Turk et al., 2000; Kidd et al., 2003). The HMT rainfall estimation curve is obtained by combining a set of simultaneous Meteosat infrared images with passive-microwave rainfall images (SSMI and AMSR sensors). In order to identify convective areas, a cross-correlation methodology is applied for the tracking of cold cloud top pixels (cloud top Infrared-channel temperature lower than $239 \mathrm{~K}$ ). Cloud pixels are tracked applying a cross-correlation method over 19 by 19 grid-cells and then the cloud pixel temperature change with time is calculated. Rainy points that are cooling in time are marked as convective according to the work of Roberts and Rutledge (2003), while the other rainy pixels are marked as stratiform. Bear in mind that in the FDDA only the precipitation type will be used, irrespective of the amounts.

Lightning discharges are also used to mark as convective pixels a $3 \times 3$ pixels zone centred at the discharge point, even if these lie outside the satellite convective area. The number of hits of each satellite image are taken within a temporal window of $20 \mathrm{~min}$ around each satellite picture.

Following Davolio and Buzzi (2004), the humidity adjustment in the model is done following certain vertical structures associated with stratiform or convective precipitation types (see Fig. 3, and Eq. 1). The sensitivity to the precise representation of the vertical profiles will be studied in Sect. 4.5. By this way, it is ensured a relaxation (by factor $\mathcal{R}(\sigma)$ ) of the model grid point mixing ratio value $\left(\mathcal{Q}_{m}(i, j, k)\right)$ to mid or low-level saturating mixing ratio $\left(\mathcal{Q}_{s}(i, j, k)\right)$ is consistent with the forcing, respectively, of stratiform or convective precipitation. The new humidity profiles are introduced in the simulations via analysis and observational nudging as implemented in the FDDA package of the MM5 model.

$$
\mathcal{Q}^{\prime}(i, j, k)=\mathcal{Q}_{m}(i, j, k)+\mathcal{R}(\sigma)\left[\mathcal{Q}_{s}(i, j, k)-\mathcal{Q}_{m}(i, j, k)\right]
$$

Nudging is only applied in the high resolution inner domain with the dynamic assimilation (assimilation of observations is done at every available observation time) during all the periods of the forecast. Configuration of the assimilation follows standards of MM5 model with a weight $\left(\mathcal{R}_{q}\right)$ of $10 \times 10^{-4}$ and a time window of $6 \mathrm{~min}$ from the time of the observation (full influence $\pm 3 \mathrm{~min}$, linear decay \pm 6 min further). The weight computation of nudging term is done every 2 model time-steps with a vertical influence of the observation $\left(\sigma_{z}\right)$ between levels of 0.001 (Cressman-type).

Ten experiments are performed for each medicane case (see Table 1). A control simulation (without humidity modification) is first performed. Two modifications of the MM5 simulations are done without FDDA technique, in which 


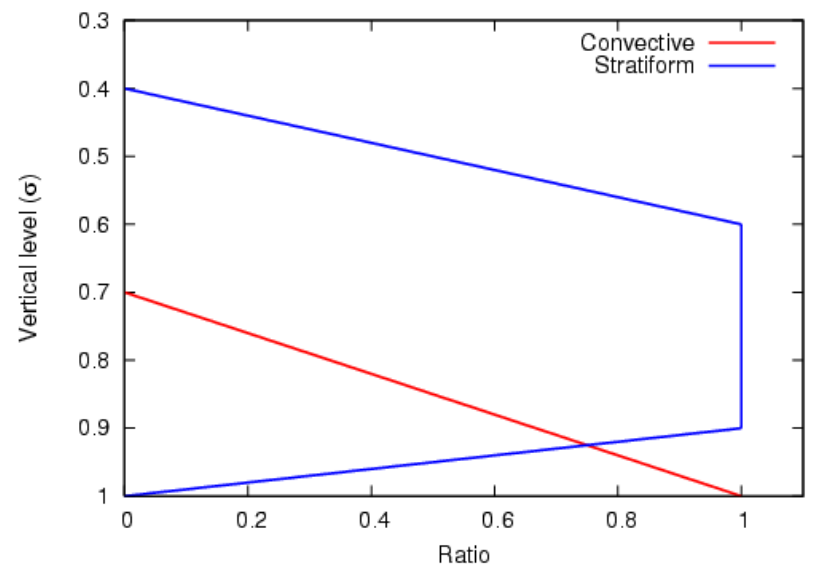

Fig. 3. Vertical profile of factor $\mathcal{R}(\sigma)$ (used in Eq. 1) for the correction of the humidity profile in the convective precipitation (red) and stratiform (blue) precipitation areas.

initial and boundary conditions for the humidity fields (i.e. analyses from ECMWF) are modified with the satellitederived information introducing stratiform/convective saturated vertical profiles according to a satellite-derived kind of precipitation. First experiment applies the modifications only to the initial condition (REGRIDmod experiment). In the second experiment, the procedure is carried out at each analysis time (00:00, 06:00, 12:00 and 18:00 UTC, REGRIDmod TOT experiment).

MM5 FDDA technique can be applied as analyses nudging. In this case, analyses grid point values drive tendencies of the model. Additionally, one can study the effect of satellite observations into the analyses. Thus, two experiments will be performed. Analysis nudging is done with the nonmodified version of the analyses (FDDA AN exp.), and with analyses in which humidity vertical profiles have been modified with satellite-based information (FDDA rhAN exp.). FDDA rhAN experiment consists of the correction of humidity profiles with satellite/lightning information only at temporal resolution of ECMWF analyses (00:00, 06:00, 12:00, 18:00 UTC).

Satellite information is obtained every $30 \mathrm{~min}$ (i.e. operational frequency of METEOSAT-5 and METEOSAT-7 geostationary satellites) with a horizontal resolution about $5 \mathrm{~km}$ in the study zone. Modifications of vertical humidity profiles are done in the lowest 12 sigma-levels. Computational memory limitations do not allow us to use the maximum temporal and spatial resolution of the satellite information together. Thus, an observational nudging with full temporal resolution and reduced horizontal resolution (OBS TOT exp.) has been performed. Four additional experiments have been performed with the highest horizontal resolution that computational resources allow under a satellite information update frequency of $1 \mathrm{~h}$ and $3 \mathrm{~h}$ (OBS $1 \mathrm{~h}$ and OBS $3 \mathrm{~h}$ experiments
Table 1. Complete set of experiments for the September 1996 case (left) and October 2003 case (right). $\Delta \boldsymbol{r}$ indicates horizontal resolution $(\mathrm{km})$ of the satellite-derived information used. $\Delta t$ indicates the frequency (hours) of assimilation into the simulations of the satellite-derived information. $\varnothing$ indicates no data assimilation. $\forall$, indicates maximum available resolution. $t_{0}$, indicates simulation start time. H: High spatial resolution. L: Low spatial resolution.

\begin{tabular}{lcc|cc}
\hline simulation & \multicolumn{2}{c|}{960912} & \multicolumn{2}{c}{031018} \\
& $\Delta \boldsymbol{r}(\mathrm{km})$ & $\Delta t(\mathrm{~h})$ & $\Delta \boldsymbol{r}(\mathrm{km})$ & $\Delta t(\mathrm{~h})$ \\
\hline control & $\emptyset$ & $\emptyset$ & $\emptyset$ & $\emptyset$ \\
REGRIDmod & $\forall$ & $t_{0}$ & $\forall$ & $t_{0}$ \\
REGRIDmod TOT & $\forall$ & 6 & $\forall$ & 6 \\
FDDA AN & $\forall$ & 6 & $\forall$ & 6 \\
FDDA rhAN & $\forall$ & 6 & $\forall$ & 6 \\
OBS TOT & 15 & $\forall$ & 22.5 & $\forall$ \\
OBS 1 h H & 3 & 1 & - & - \\
OBS 1 h L & 6 & 1 & 15 & 1 \\
OBS 3 h H & 3 & 3 & 7 & 3 \\
OBS 3 h L & 6 & 3 & 15 & 3 \\
\hline
\end{tabular}

at $\mathrm{H}$ or $\mathrm{L}$ spatial resolution). Table 1 shows the specific configuration of each experiment. There is not a "OBS $1 \mathrm{~h} \mathrm{H}$ " experiment for the October 2003 case due to computational limitations.

The above experiments will be compared against the control one with regard to the characteristics of the simulated medicanes and in terms of several meteograms. These meteograms are located at the genesis and evolution areas of each medicane and are drawn for different variables such as convective available potential energy (CAPE), precipitable water, surface latent heat flux and wind characteristics.

In order to provide an objective way to compare simulated and satellite-derived trajectories and as an attempt to simplify the large amount of information, some statistical parameters are proposed.

\subsection{Statistical parameters}

\subsubsection{Minimum BIAS}

The BIAS $_{\text {dist }}$ between satellite-derived medicane trajectory $\mathrm{TRJ}_{\text {ref }}$ and simulation trajectory used to compare $\mathrm{TRJ}_{\text {com }}$ is given by:

$$
\begin{aligned}
& \text { BIAS }_{\mathrm{dist}}=\frac{1}{n} \sum_{t=1}^{n} \delta r(t) \\
& \delta r(t)=\sqrt{\delta x(t)^{2}+\delta y(t)^{2}}
\end{aligned}
$$

where $\delta r(t)$ is the distance at time $t$ between $\mathrm{TRJ}_{\mathrm{ref}}$ and $\mathrm{TRJ}_{\text {com. }}$. In the expression (3) $\delta \mathfrak{x}(t)=\mathfrak{x}_{\text {ref }}(t)-\mathfrak{x}_{\mathrm{com}}(t)$, difference between $\mathfrak{x}=[x, y]$ coordinates of the trajectories. Assuming differences in the morphologies and evolving 
zones of the trajectories, as well as different speeds of evolution of the compared medicanes, BIAS dist $_{\text {would generally }}$ present a dependence on temporal shift of TRJ $\mathrm{J}_{\mathrm{com}}$. Temporal shift $\tau$ for which BIAS $_{\text {dist }}$ becomes minimum (see Eq. 4), provides an idea of this difference between translational speeds. Temporal range $\tau=[-n / 2, n / 2]$ is used ( $n$ number of total time-steps of length $\Delta t$ ) in the inspection for the adequate $\tau$ that minimises BIAS $_{\text {dist }}$. Taking as inspection limits $\pm n / 2$, it is ensured a minimum number of trajectories values $(n)$ for the statistical computation:

$\mathrm{BIAS}_{\mathrm{dist}}^{\min }=\min \left[\frac{1}{n} \sum_{t=1}^{n} \sqrt{\delta x(t, \tau)^{2}+\delta y(t, \tau)^{2}}\right]$

where $\delta \mathfrak{x}(t, \tau)=\mathfrak{x}_{\text {ref }}(t)-\mathfrak{x}_{\text {com }}(t \pm \tau)$, differences between coordinates $\mathfrak{x}=[x, y]$ of trajectory $\mathrm{TRJ}_{\text {ref }}$ at time $t$ and trajectory $\mathrm{TRJ}_{\text {com }}$ shifted $\pm \tau=n \Delta t, n$ time steps of $\Delta t$ length.

\subsubsection{Distance correlation}

Correlation (classical definition, or Pearson correlation) between satellite-derived trajectory and simulated one is given by:

$\mathcal{R}=\frac{<\mathcal{D}_{\text {ref }} \mathcal{D}_{\text {com }}>-<\mathcal{D}_{\text {ref }}><\mathcal{D}_{\text {com }}>}{\sigma_{\mathcal{D}_{\text {ref }}} \sigma_{\mathcal{D}_{\text {com }}}}$

where $\sigma_{\mathcal{D}_{\chi}}=\sqrt{\left\langle\mathcal{D}_{\chi}^{2}>-<\mathcal{D}_{\chi}\right\rangle^{2}}$, standard deviation of trajectory $\chi$, and $\left\langle\mathcal{D}_{\chi}\right\rangle$ average position of trajectory $\chi=\left[\right.$ ref, com], and $\left\langle\mathcal{D}_{\chi}^{2}\right\rangle$, averaged quadratic distance of trajectory $\chi$ :

$$
\begin{aligned}
<\mathcal{D}_{\chi}> & =\frac{1}{n} \sum_{t=1}^{n} \mathcal{D}_{\chi}=\frac{1}{n} \sum_{t=1}^{n} \sqrt{x(t)_{\chi}^{2}+y(t)_{\chi}^{2}} \\
<\mathcal{D}_{\chi}^{2}> & =\frac{1}{n} \sum_{t=1}^{n} \mathcal{D}_{\chi}^{2}=\frac{1}{n} \sum_{t=1}^{n} x(t)_{\chi}^{2}+y(t)_{\chi}^{2} \\
<\mathcal{D}_{\text {ref }} \mathcal{D}_{\text {com }}> & =\frac{1}{n} \sum_{t=1}^{n} \mathcal{D}_{\text {ref }} \mathcal{D}_{\text {com }}
\end{aligned}
$$

\subsubsection{Pure coordinate correlation}

It is a classical or Pearson correlation (see Eq. 5) between observed and simulated trajectory coordinate series. It is computed as the correlation of two vectors of one dimension ( $\mathcal{R}_{\text {ref/com }}$ ) constructed by the $x$-coordinates followed by the $y$-values (Eq. 12). In order to compute this correlation different statistics are defined: $\sigma_{\mathcal{R}_{\chi}}=\sqrt{\left\langle\mathcal{R}_{\chi}^{2}>-<\mathcal{R}_{\chi}>^{2}\right.}$, standard deviation of trajectory $\chi$, where $\left\langle\mathcal{R}_{\chi}\right\rangle$ is the average value of trajectory $\chi=\left[\right.$ ref, com] (Eq. 10), and $\left\langle\mathcal{R}_{\chi}^{2}\right\rangle$, quadratic average value of trajectory $\chi$ :

$$
\mathcal{R}_{\chi}=\frac{1}{2 n} \sum_{t=1}^{2 n} R(t)_{\chi}
$$

$$
\begin{gathered}
\mathcal{R}_{\chi}^{2}=\frac{1}{2 n} \sum_{t=1}^{2 n} R(t)_{\chi}^{2} \\
\mathcal{R}_{\text {ref }} \mathcal{R}_{\text {com }}=\frac{1}{2 n} \sum_{t=1}^{2 n} R(t)_{\text {ref }} R(t)_{\text {com }}
\end{gathered}
$$

where

$$
R_{\chi}=\left(\mathcal{X}_{\chi}, \mathcal{Y}_{\chi}\right)=\left(x_{\chi}^{t=1}, \cdots, x_{\chi}^{t=n}, y_{\chi}^{t=1}, \cdots, y_{\chi}^{t=n}\right)
$$

\subsubsection{Bias correction}

The total bias BIAS $S_{\text {ref }}^{\text {com }}$ between compared and reference trajectories is defined as:

$\operatorname{BIAS}_{\mathrm{ref}}^{\mathrm{com}}=\operatorname{BIAS}(x)_{\mathrm{ref}}^{\mathrm{com}}+\operatorname{BIAS}(y)_{\mathrm{ref}}^{\mathrm{com}}$

where BIAS $(\mathfrak{x})_{\text {ref }}^{\mathrm{com}}$, BIAS of coordinate $\mathfrak{x}=[x, y]$ is given by:

$\operatorname{BIAS}(\mathfrak{x})_{\mathrm{ref}}^{\mathrm{com}}=\frac{1}{n} \sum_{t=1}^{n} \mathfrak{x}(t)_{\mathrm{ref}}-\mathfrak{x}(t)_{\mathrm{com}}$

Trajectory of comparison $\mathrm{TRJ} \mathrm{J}_{\mathrm{com}}=\left(\mathcal{X}_{\text {com }}, \mathcal{Y}_{\text {com }}\right)$ is corrected with the BIAS $(\mathfrak{x})_{\text {ref }}^{\mathrm{com}}$ according to:

$$
\begin{aligned}
& \mathrm{TRJ}_{\mathrm{com}}= \\
& \left(\mathcal{X}_{\text {com }}-\operatorname{BIAS}(\mathcal{X})_{\text {ref }}^{\text {com }}, \mathcal{Y}_{\text {com }}-\operatorname{BIAS}(\mathcal{Y})_{\text {ref }}^{\text {com }}\right)
\end{aligned}
$$

\subsubsection{BIAS temporal lag correction}

Following BIAS ref $_{\text {com }}$ correction of trajectory TR $\tilde{J}_{\text {com }}$, a set of temporal shifts are performed in the trajectory $\left(\mathrm{TR \tilde {J } _ { \text { com } }}( \pm \tau)\right.$ ) in order to obtain the $\tau$ value from which the pure coordinate correlation PR becomes the highest one ( $\mathrm{PR}_{\text {bias }}^{\max }$, see expression 16). The obtained $\tau$ value provides a guidance of the temporal shift between simulated and observed trajectories:

$$
\begin{aligned}
& \mathrm{PR}_{\text {bias }}^{\max }=\max (\mathrm{PR})[ \pm \tau]= \\
& \max \left(\left[<\mathcal{X}_{\text {ref }}>-<\tilde{\mathcal{X}}( \pm \tau)_{\mathrm{com}}>\right]+\right. \\
& \left.\left[<\mathcal{Y}_{\text {ref }}>-<\tilde{\mathcal{Y}}( \pm \tau)_{\text {com }}>\right]\right)
\end{aligned}
$$

Simulated medicanes show slower translational speeds than the satellite observed ones (see control simulation results in Figs. 4 and 5). A new method to evaluate the temporal shift of two trajectories is put in practice here. The temporal shift between satellite-observed and simulated trajectories of the medicanes is objectively studied by means of the temporal dependence of bias and correlations (see BIAS dist $_{\text {ist }}$ and $\mathrm{PR}_{\text {bias }}^{\max }$ definitions in Eqs. (4) and (16), respectively). These statisti$\mathrm{cal}$ indices are iteratively recomputed using simulated trajectories that are positively or negatively displaced in time (e.g. an advanced trajectory is obtained when a simulated position at time $t, \boldsymbol{x}^{t}$, is changed to the position at time $t+n \Delta t$ ). Temporal shift between trajectories will correspond with that shift 

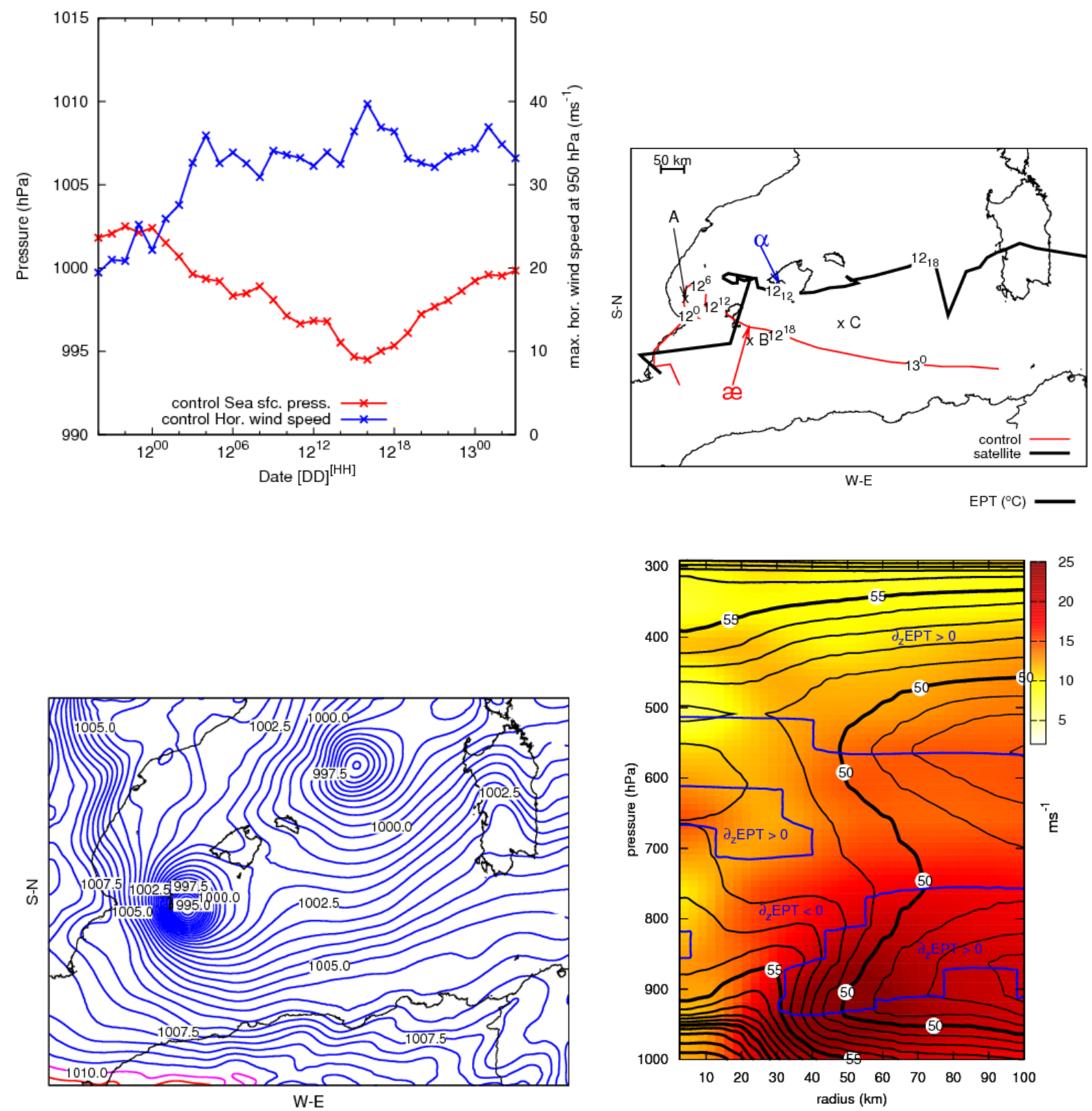

Fig. 4. MM5 control simulation results. Evolution of the central pressure (left top, in $\mathrm{hPa}$ as red line), and maximum horizontal wind speed at $950 \mathrm{hPa}\left(\mathrm{ms}^{-1}\right.$, blue line). Simulated medicane trajectory (top right, red line indicating time $[D D]^{[H H]}$ format) compared with the satellite-based trajectory (thick black line, $[D D]_{[H H]}$ format). Simulated deepest medicane on 12 September at 16:00 UTC (bottom left) and azimuthally averaged vertical cross section from the centre of medicane at deepest moment (bottom right, horizontal wind speed shaded in colours, equivalent potential temperature in lines and superimposed, convective instability $\left(\partial_{z} \mathrm{EPT}<0\right)$ in blue line). A, B, C points in top-right panel indicate where meteograms have been obtained. æsymbol give position of medicane. Point $\alpha$ is where the barograph is located.

$n \Delta t(\Delta t=1 \mathrm{~h})$ that minimises bias and maximises correlation scores. The BIAS informs us about the spatial proximity of the simulated and satellite-observed trajectories. Correlation is focused on the similarity between the morphologies of trajectories.
Taylor diagrams of simulated and satellite-derived trajectories will be also used. Taylor diagrams (Taylor, 2001) of the simulated trajectories taking as reference the satellitederived trajectory (with more than 30 values used in the statistics) are plotted. Computations are made only if medicane position can be retrieved from satellite imagery. Taylor 

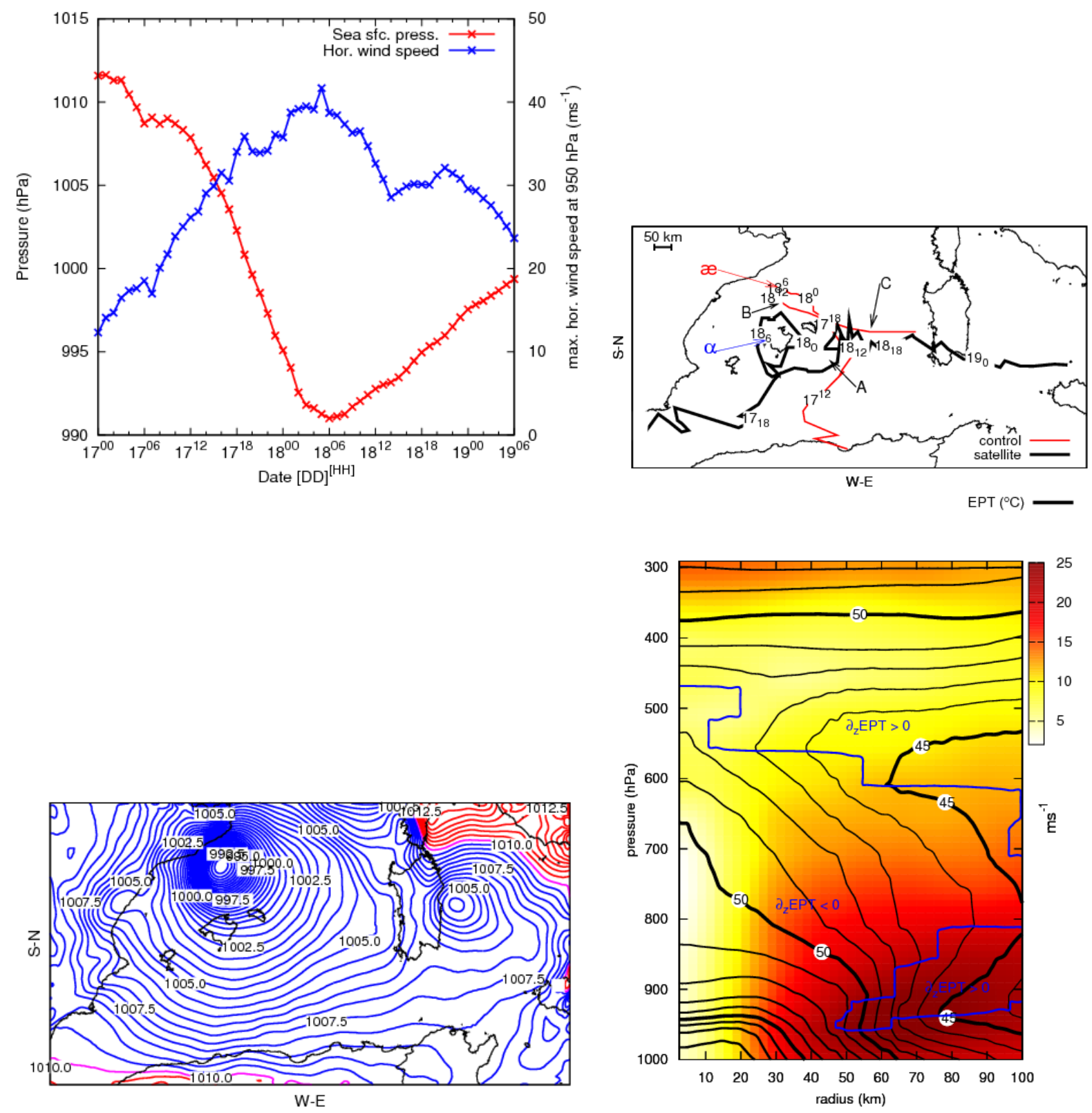

Fig. 5. As in Fig. 4, but for October 2003 case and strongest moment on 18 October at 06:00 UTC.

diagrams are plots in which two statistical parameters are represented. They use polar coordinates in which the angle is given by the correlation $(\mathcal{R})$ between two series of data and the radius is given by the standard deviation $\left(\sigma_{\mathrm{com}}\right)$. If an overall bias correction is applied, it is found that the distance between the position of a point in the diagram and the standard deviation of the reference data series is the root mean square error (RMSE, in the present study this correction has not been done). Taylor diagrams show the higher sensitivity to the FDDA methods for the standard deviation than for the correlation. That means that the trajectories suffer a higher change in its morphology and zone of evolution than in their temporal synchronism with respect to the observed one. No smoothing of refilling techniques have been applied on the satellite-observed trajectories of the medicanes. That is, satellite trajectories are used as they are retrieved from satellite imagery. When no satellite image is available (as it occurs in the beginning phase of September 1996 medicane), then the trajectory is not defined. 

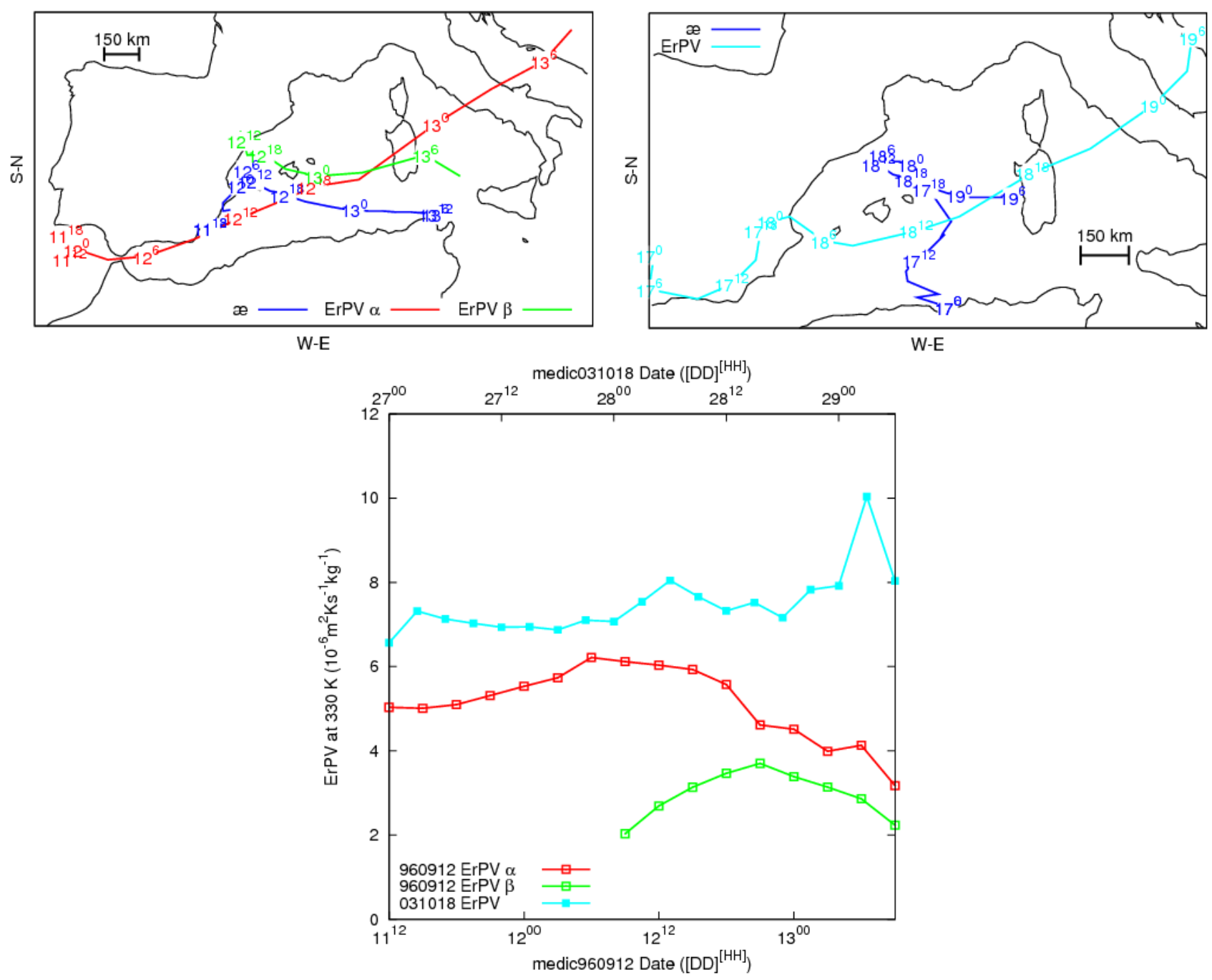

Fig. 6. Evolution of Ertel PV maxima on the $330 \mathrm{~K}$ isentropic surface (red) related to the evolution of September 1996 (top left) and October 2003 (top right) medicane (blue) at different time steps (in $[D D]^{[H H]}$ format). In September 1996 simulation two maxima appear, $\alpha$ (red line), and $\beta$ (green line). Temporal evolution of the Ertel PV value of each maxima (bottom).

\section{Results}

\subsection{Control simulations}

Control simulations of the two cases show formation of the system but a poor agreement between simulated and observed trajectories (see Figs. 4 and 5). Both medicanes are formed under the eastern sector of an upper-level trough (see Fig. 2), that is a characteristic of the baroclinic growing of disturbances (Hoskins et al., 1985). However, these two medicanes do not closely relate with the upper-level disturbances since their trajectories differ at least with respect to the trajectory of the maximum vorticity centre of the upper-level trough (see Fig. 2). In both cases, the MM5 simulation shows a pronounced sea-level fall similar to that registered in baro- graphs (see top left panels in Figs. 7 and 8). However, the pressure minimum is simulated at wrong places.

The vertical structures of both simulated medicanes are very similar (see bottom right panels in Figs. 4 and 5). In both cases, a convectively stable zone is elongated at low-mid levels (between $950 \mathrm{hPa}$ and $750 \mathrm{hPa}$ ) at a significant distance (30 km in September 1996 and $50 \mathrm{~km}$ in October 2003) from the centre. In almost all other sectors of the storm, convective instability reaches $550 \mathrm{hPa}$ and thus favours the formation of deep convection. This structure of convective instability would confirm the tropical-like characteristics of the medicanes (with similarities with hurricanes Emanuel, 1986; Zhang et al., 2002). In general, there is a light correlation between low/high central pressure centres and strong/weak horizontal winds (see Figs. 9 and 12). According to the tropical 

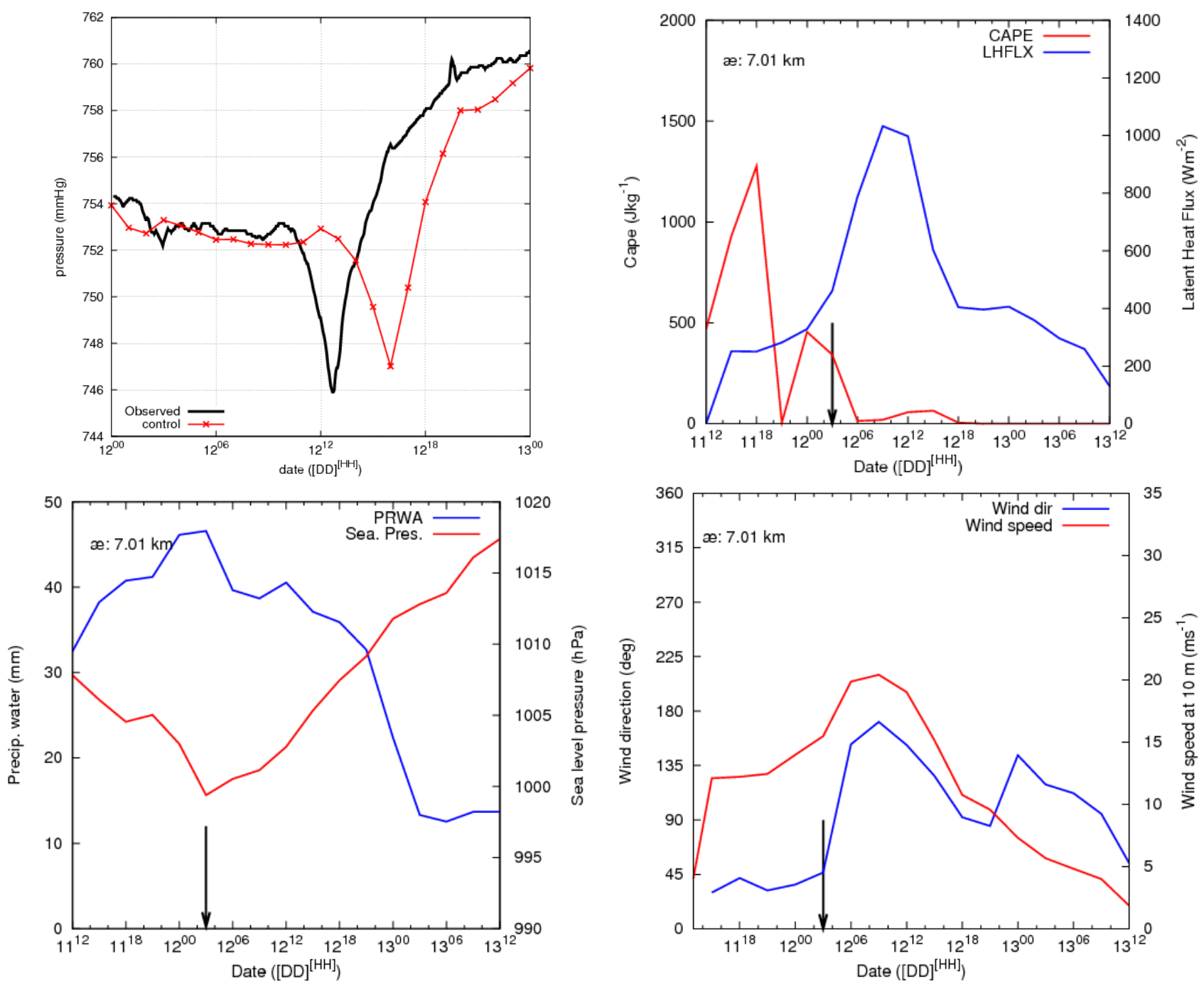

Fig. 7. Comparison between barograph observed pressure (black line, at point $\alpha$, see top left panel in Fig. 4) and simulated (red line, taken at the point where medicane reaches its deepest central pressure value æ). Meteograms at point A (see top right panel of Fig. 4) for the simulation of September 1996 medicane. Top right panel: convective available potential energy (CAPE, $\mathrm{J} \mathrm{kg}^{-1}$, red line, left y-axis) and surface latent heat flux ( $\mathrm{W} \mathrm{m}^{-2}$, blue line, red y-axis). Bottom left panel: Precipitable water ( $\mathrm{mm}$, blue line, left y-axis) and sea level pressure (hPa, red line, right y-axis). Bottom right panel: $10 \mathrm{~m}$ wind direction (deg, red, left y-axis) and wind speed (ms ${ }^{-1}$, blue, right $\mathrm{y}$-axis). Vertical arrows indicated the time at which the simulated medicane passes closest to the point. Distances ( $\mathrm{km})$ of the medicane centre " $æ$ " to the point are indicated at the top left corner of the graphs.

characteristics of medicanes, it would be assumed that some correspondence between central pressure value and horizontal wind speed occurs, as in the hurricane cases (Emanuel, 2000).

Trajectories of upper-level vorticity maximum and medicanes are not clearly linked, showing a low correlation between these two features (see Fig. 6). On the September 1996 episode, medicane remained static until an upper-level vorticity maximum reached the zone (where a secondary maximum, labelled $\beta$ appeared, with a different trajectory). The secondary $\beta$ maximum evolves at the beginning much more closely to the medicane trajectory and presents a diabatic genesis (not shown). In contrast, October 2003 medicane follows an independent trajectory until an upper-level vorticity maximum reaches the zone and seems to drag the later phase of the medicane trajectory. At the same time, upperlevel vorticity maximum for the October 2003 case presents mainly an adiabatic evolution, whereas upper-level vorticity maxima for September 1996 case exhibits more diabatic-like.

The October 2003 medicane evolution does not seem to follow the upper-level disturbance so clearly, as the previous case. The Medicane and centre of the trough do not 

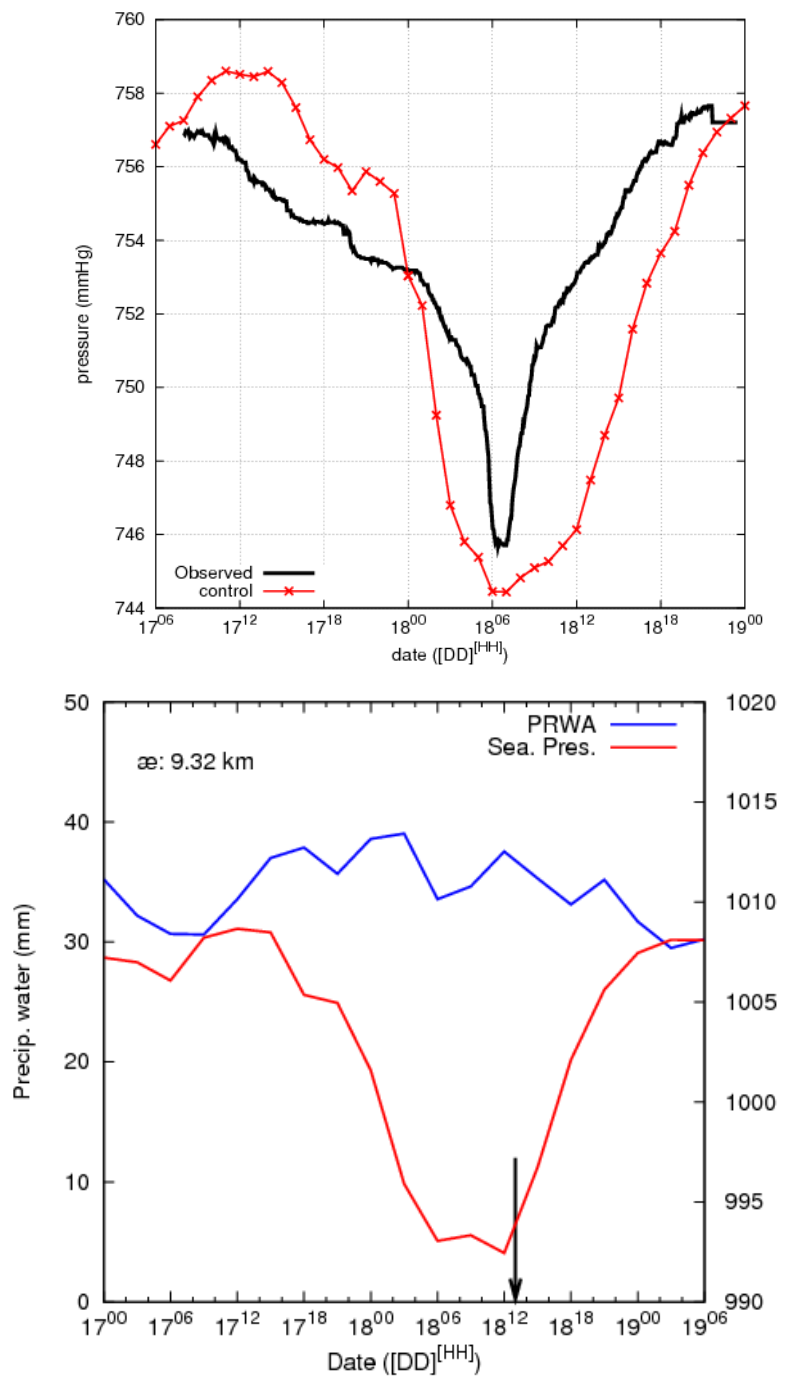

Fig. 8. As in Fig. 7, but for the October 2003 case.

evolve simultaneously in this case. The closest approach between both systems does not reach $200 \mathrm{~km}$ (see right panel in Fig. 6). Therefore, October 2003 medicane might be more influenced by the general flow pattern associated with the upper-level trough than by the precise movement of its centre of maximum vorticity.

Experiments "FDDA rhAN", "OBS TOT", "OBS 1h H/L" and "OBS $3 \mathrm{~h} \mathrm{H/L"} \mathrm{imply} \mathrm{a} \mathrm{direct} \mathrm{impact} \mathrm{of} \mathrm{the} \mathrm{satel-}$ lite/lightning information into the simulations. Only in these 6 experiments changes in the vertical humidity profiles are introduced at specific grid points and time steps, thus directly affecting the humidity tendency term in the model equations. In order to analyse the effect of data assimilation into the simulations, meteograms for these 6 experiments at one particular model grid point will be drawn and discussed.

Control simulation meteograms at different locations along the medicanes path (see Figs. 7 and 8) show a clear sig-
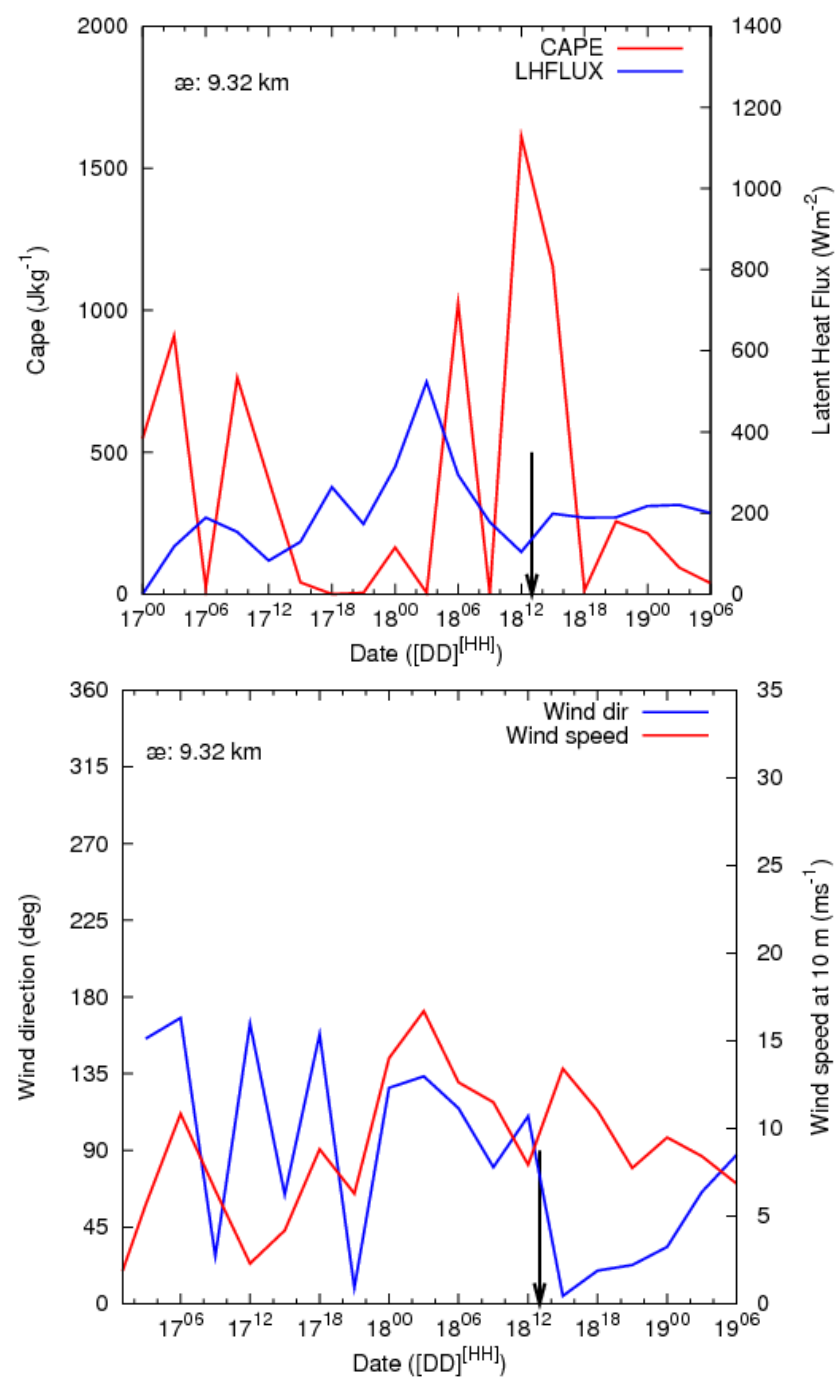

nature of the approach of the medicanes (similar behaviour is observed for the meteograms at other points, not shown). Increase of the surface fluxes and precipitable water is a signature of the hurricane characteristics of the medicane (Emanuel, 1986). The accumulated potential energy would be used in the intensification of the system throughout convection, reflected as a decrease of CAPE values after the passage of the medicane over the area. In the same sense, a pressure fall and a significant change on the wind direction and its strength are observed. The strong surface winds increase surface fluxes and thus water vapour content in the lower troposphere from which cloud formation will be reinforced. Meteograms at other model grid points corresponding to later phases of the evolution of the medicanes show a similar behaviour (not shown). 

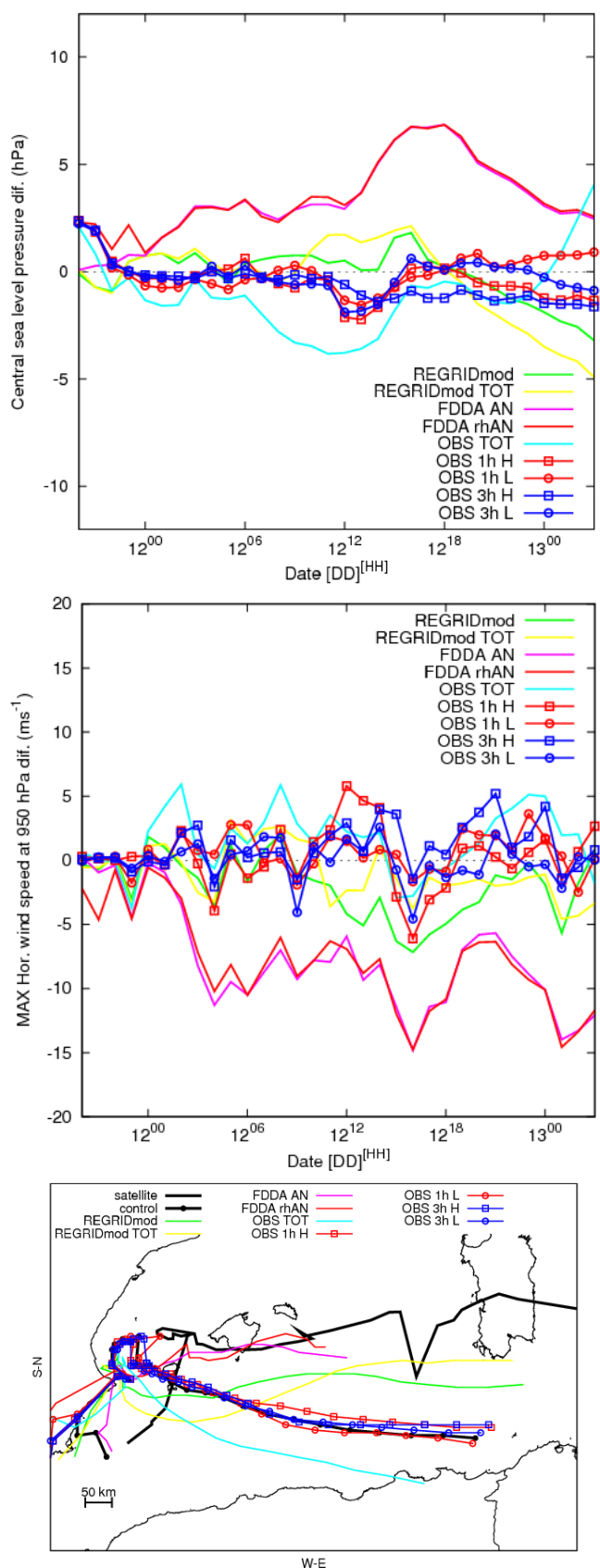

Fig. 9. September 1996 medicane simulations. Top: Central sea level pressure $(\mathrm{hPa})$ referred to control value $\left(\mathcal{P r e s}_{\text {sim }}-\mathcal{P}\right.$ res $\left._{\text {control }}\right)$. Middle: Maximum horizontal wind speed $\left(\mathrm{ms}^{-1}\right)$ at $950 \mathrm{hPa}$ within a radii of $200 \mathrm{~km}$ from the centre of the storm, referred to control value. Bottom: Trajectories of simulated medicanes. Results are shown for the set of experiments using lines with different colours: satellite trajectory (black line). Control simulation (black with circles), REGRID mod (green), REGRID mod TOT (yellow), FDDA AN (pink), FDDA rhAN (orange), OBS TOT (light blue), OBS $1 \mathrm{~h} \mathrm{H}$ (red line with squares), OBS $1 \mathrm{~h} \mathrm{~L}$ (red line with circles), OBS $3 \mathrm{~h} \mathrm{H}$ (blue line with squares), OBS $3 \mathrm{~h} \mathrm{~L}$ (blue line with circles).

\subsection{September 1996 assimilation experiments}

Simulations of the September 1996 case with the satellite/lightning information show stronger medicanes than the control one during its mature phase (see top and middle panels in Fig. 9), although weaker medicanes are obtained at the later stages of the simulations. The medicane trajectories do not show high changes, partially explained by the low effect of the data assimilation on the trajectories of the upper-level disturbances. Indeed, upper-level vorticity centres show a weak sensitivity on humidity experiments (not shown). Interestingly, the mature phase of medicanes for all the experiments occurs at the same time, on 12 September at 12:00 UTC.

The largest differences on trajectory and central pressure value with respect to the control one are obtained with the experiment "FDDA AN" and "FDDA rhAN" (nudging of ECMWF analyses). In these simulations (pink and orange lines in Fig. 9), simulated medicanes are significantly weaker (they vanish before 13 September at 00:00 UTC) and their trajectories differ significantly from the other ones (see bottom panel in Fig. 9). In these experiments, the results are forced to be very similar to the ECMWF analyses, and ECMWF analyses do not fully capture the structure of the medicane owing to a poor horizontal resolution (ECMWF analyses at that time were truncated at $\mathrm{T} 213,0.5625^{\circ}$ degrees of horizontal resolution), however, since the analyses correctly capture the upper-level disturbance, and their effects are nested down by the MM5 mesoscale model, it should be expected that a medicane trajectory is in agreement with the satellite-derived one. Deeper simulated medicanes are obtained when the observational nudging is applied (experiments labelled OBS TOT, OBS $1 \mathrm{~h} \mathrm{H} / \mathrm{L}$, OBS $3 \mathrm{~h} \mathrm{H} / \mathrm{L}$; light blue, red and blue lines with empty squares or circles in Fig. 9).

September 1996 deepest medicane is obtained by experiment "OBS TOT" (humidity modification at every time step with the maximum computer-allowed ${ }^{2}$ spatial resolution, in this case $15 \mathrm{~km}$; light blue line in Fig. 9). Sensitivity of the observational nudging on the temporal and spatial resolution is analysed with four experiments that combine satellite/lightning information at two temporal ( 1 and $3 \mathrm{~h})$ and spatial ( 3 and $6 \mathrm{~km}$ ) resolutions "OBS $1 \mathrm{~h} / 3 \mathrm{~h} \mathrm{H} / \mathrm{L}$ " experiments. The four trajectories of these experiments are very similar. The evolution of central sea level pressure shows similar behaviour between assimilations at the same horizontal resolution (similar curves between OBS $1 \mathrm{~h} / 3 \mathrm{~h} \mathrm{H}$ and similar curves between OBS $1 \mathrm{~h} / 3 \mathrm{~h} \mathrm{~L}$ ). At the same time, evolution of the wind speed presents wider differences with respect to the control one in the simulations with the assimilation of observations at higher spatial resolution (exp. OBS $1 \mathrm{~h} / 3 \mathrm{~h} \mathrm{H}$, red and blue lines with empty squares).

\footnotetext{
${ }^{2}$ on a PC Linux cluster with central and auxiliary nodes all with $4 \mathrm{~Gb}$ of memory
} 

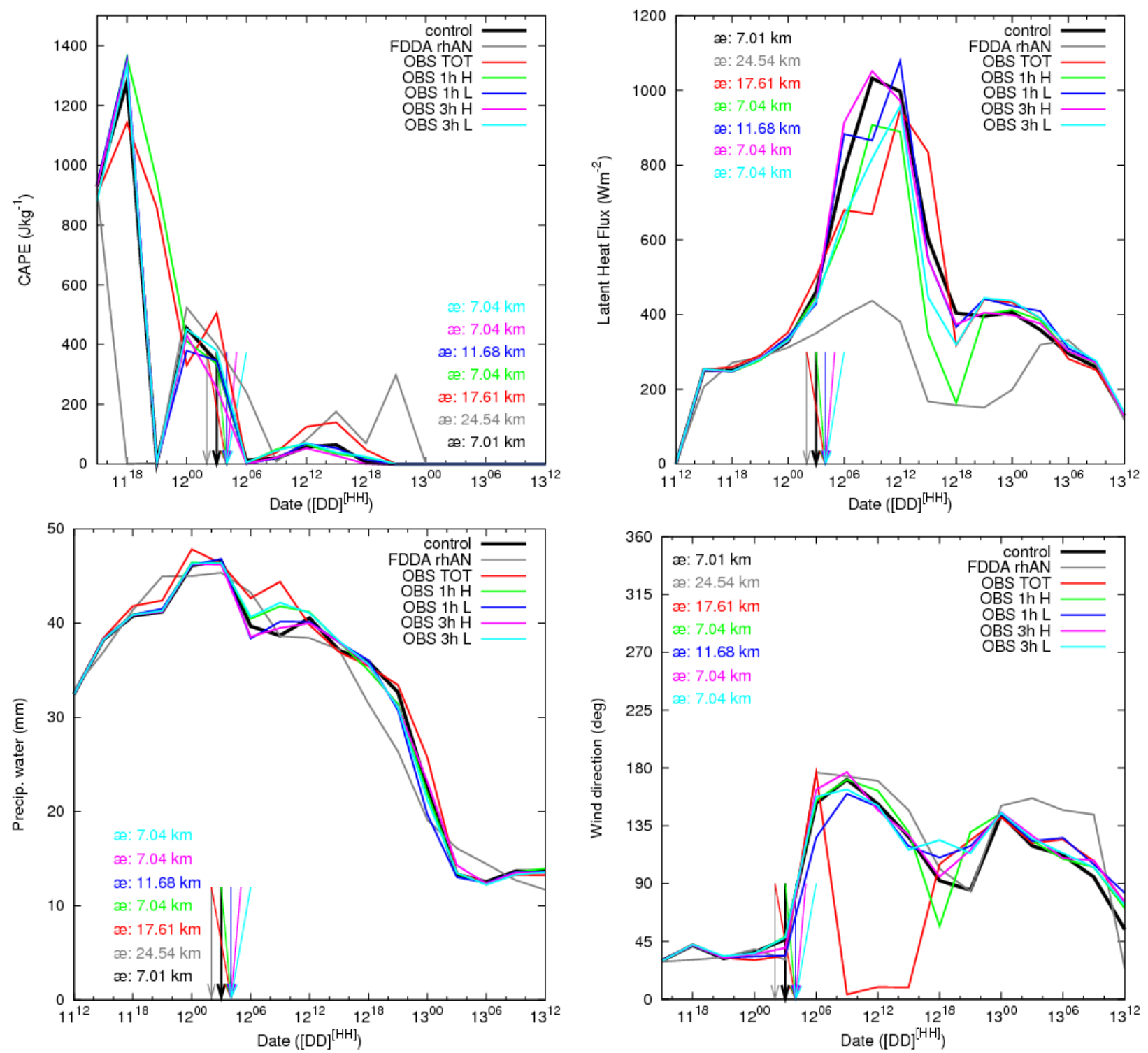

Fig. 10. Evolution at point A (top right panel of Fig. 4) during September 1996 simulation of CAPE ( $\mathrm{kg}^{-1}$, top left), latent heat flux (W $\mathrm{m}^{-2}$, top right), precipitable water (mm, bottom left) and wind direction (bottom right). For control simulation (black), FDDA rhAN (grey), OBS TOT (red), OBS $1 \mathrm{~h} \mathrm{H}$ (green), OBS $1 \mathrm{~h} \mathrm{~L}$ (blue), OBS $3 \mathrm{~h} \mathrm{H}$ (pink) and OBS $3 \mathrm{~h}$ L (light blue). Vertical arrows indicate the time when the simulated medicane $(\mathfrak{x})$ passes closest to the point A. Distance is given in km (with same colour as lines).

However, experiment "OBS $1 \mathrm{~h} \mathrm{~L}$ " (red line with empty circles) presents a stronger dissipation rate of the medicane than the lower temporal resolution experiment.

No significant differences with respect to the control results are obtained in the evolutions of variables shown in meteograms at the genesis zone of September 1996 after the assimilation of satellite/lightning information (see Fig. 10). The strongest differences are obtained in FDDA rhAN and OBS TOT experiments.

The Taylor diagram of the trajectories shows how the implementation of FDDA on 960912 case improves trajectories with higher correlations and lower standard deviations (ex- cept for OBS TOT experiment), with a higher impact on the standard deviation.

The September 1996 episode exhibits a strong sensitivity of BIAS $_{\text {dist }}^{\min }$ on the temporal shift. This case has a symmetric response to advances/delays of the simulated trajectories. The lowest $\mathrm{BIAS}_{\mathrm{dist}}^{\min }$ values for almost all the experiments are obtained without the addition of a temporal shift in the simulated trajectories. For September 1996 medicane, the lowest BIAS $_{\text {dist }}^{\min }$ values are obtained in the experiments that do not use observation nudging (labelled REGRIDmod, REGRIDmod TOT, FDDA AN, FDDA rhAN). 

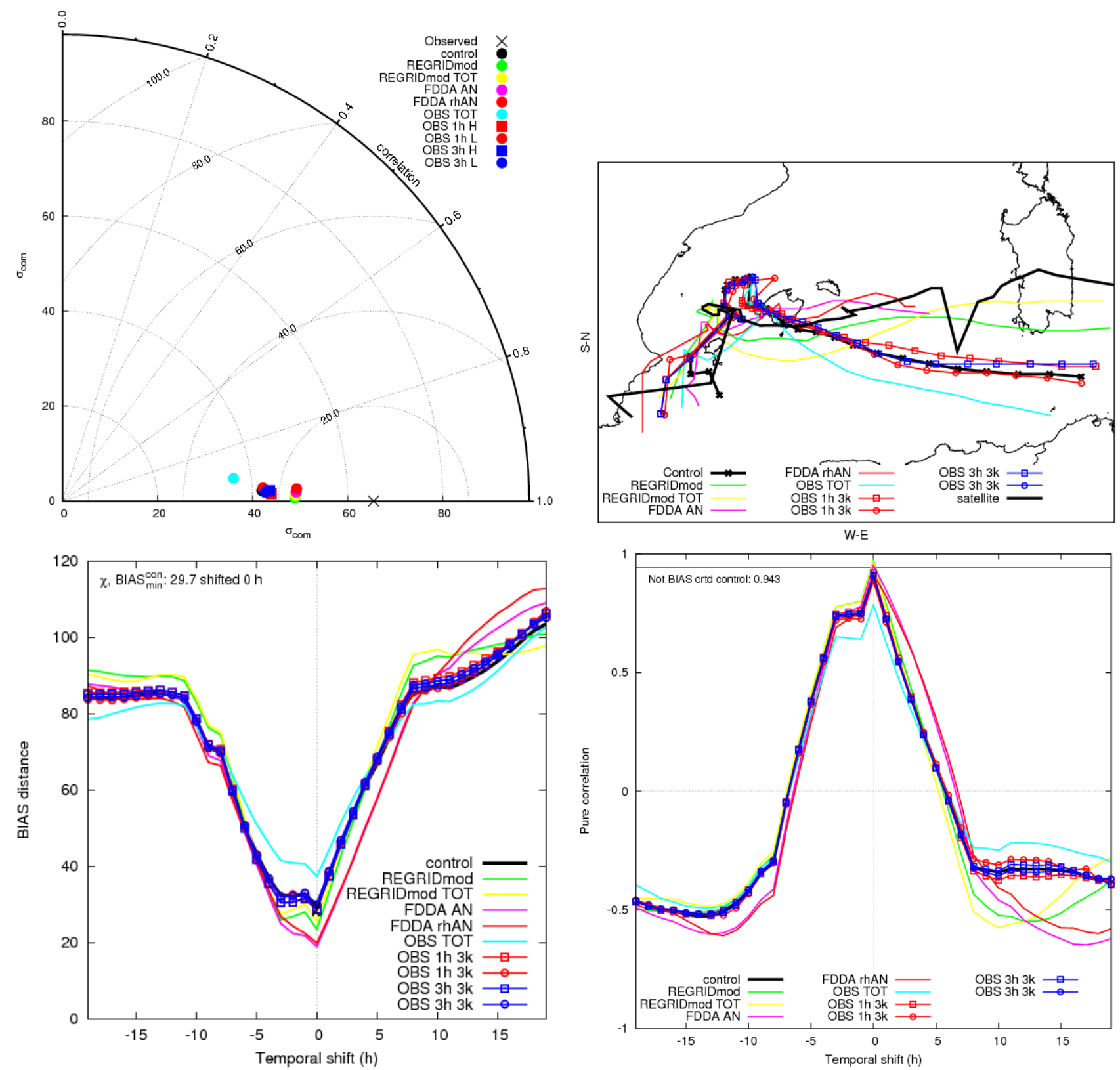

Fig. 11. Statistics of trajectories for the September 1996 case. Top left panel: Taylor diagrams as polar coordinate diagrams where $\sigma_{\text {com }}$ (standard deviation between correlative distances to the origin of coordinates) establishes the radius. $\mathcal{R}$, correlation between trajectories, establishes the angle respect to the abscissas. Root Mean Square Error (RMSE) is the distance between simulation dots and standard deviation of the observed trajectory (black cross). Top right panel: BIAS corrected simulated trajectories (i.e. bias is removed by translation of the trajectories according to the spatial satellite-derived path) for each experiment. Solid black line is the satellite trajectory. Bottom left panel: Dependence of the BIAS $\min _{\text {dist }}$ on the temporal shift between trajectories. Negative values mean temporal advances of the simulated trajectory and positive values mean delays. $\chi$ is the value of the minimum $B I A S_{\text {dist }}^{\min }$ for the control trajectory obtained for a given temporal shift. Bottom right panel: Dependence of the pure coordinate correlation PR ${ }^{\text {bias }}$ (bias corrected) for each experiment as function of temporal shift, solid black line is the correlation for the control simulation without BIAS correction. Colour codification of lines is the same as in Fig. 9.

No significant improvements of the BIAS corrected "pure coordinate correlation" ( $\mathrm{PR}_{\text {bias }}^{\max }$ ) are obtained when simulated trajectories are temporally advanced or delayed (see Fig. 11).
The introduction of a positive/negative temporal displacement in the September 1996 simulations produces a clear decrease of the correlation. No experiment or temporal shift 
gives better correlation results than the correlation attained by the control simulation without BIAS correction (horizontal solid black line in Fig. 11).

\subsection{October 2003 assimilation experiments}

As in September 1996 medicane, no significant modification on medicane temporal evolution has been derived from the assimilation experiments. Thus, the mature state of resulting medicanes is almost found at about the same time as for the control experiment on 18 October at 06:00 UTC.

Nevertheless, the October 2003 case reflects a higher influence of the FDDA technique on the simulations (see Fig. 12). There are differences between experiments larger than $10 \mathrm{hPa}$ in the central pressure value and $10 \mathrm{~ms}^{-1}$ for the maximum horizontal wind speeds. Upper-level trough trajectories do not differ significantly during the initial phase, these differences become larger at later stages of the episode (not shown). All simulated medicanes become weaker and with lower wind speeds (except short periods of experiments OBS TOT and OBS $3 \mathrm{~h} \mathrm{~L}$, light blue and blue line with empty circles of Fig. 12).

Meteograms at the genesis zone of October 2003 case show lower values of some variables with respect to control simulation (see Fig. 13). Similar behaviour of the variables is observed in the meteograms at other points, (not shown).

The October 2003 episode presents temporally the strongest simulated medicanes with experiments OBS TOT and OBS $3 \mathrm{~h} \mathrm{~L}$. At the same time, observational nudging with observational data at similar temporal resolutions (exp. OBS $3 \mathrm{~h} \mathrm{H} / \mathrm{L}$ ) offers similars results.

The FDDA methodology worsens trajectories of the October 2003 simulations (see Fig. 14) according to the increase of the pseudo-RMSE (not bias correction has been applied) and decrease of correlation between simulated and observed trajectories, having a significant effect on the standard deviation. However, experiments "OBS TOT" improves both indices. Better results with "OBS TOT" experiment are associated with better temporal correspondence of saturated grid points and satellite information. This more realistic representation of satellite information would lead to a more realistic trajectory of the medicane. It is notorious, the negative correlation value of REGRID mod experiment.

The October 2003 presents a clear decrease of BIAS $S_{\text {dist }}^{\text {min }}$ when simulated trajectories are temporally delayed with respect to the satellite one. A general delay of about $18 \mathrm{~h}$ reduces almost to half the bias (BIAS dist $_{\text {ist }}$ ) between simulated and observed trajectories.

Some of the simulations improve the pure coordinate correlation between trajectories, but the temporal shift makes the results worse, even produces negative correlation values (see Fig. 14). A secondary maximum of correlation with a delay of $18 \mathrm{~h}$ is obtained in concordance with $\mathrm{BIAS}_{\text {dist }}^{\min }$ results.
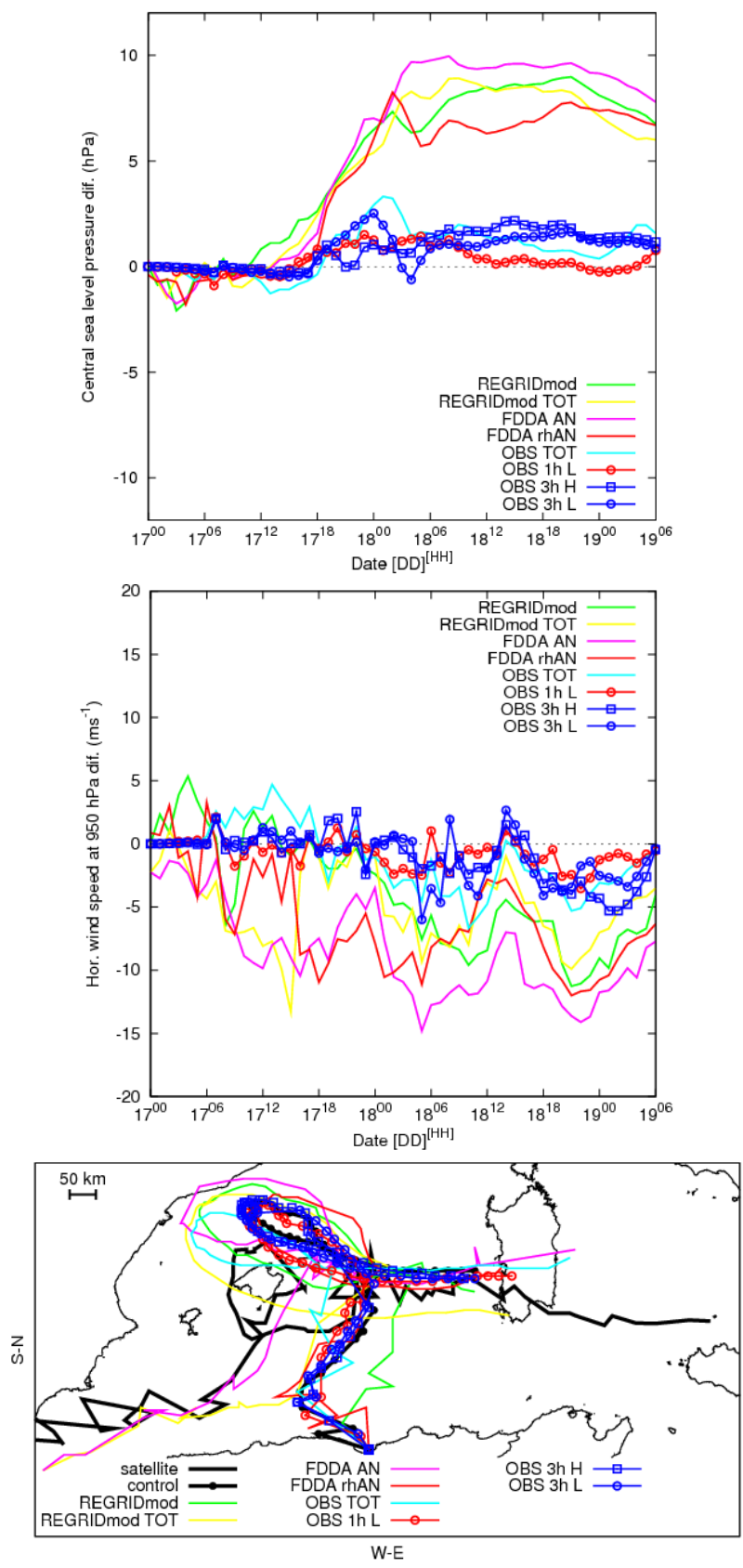

Fig. 12. As in Fig. 9, but for the October 2003 medicane.

\subsection{Intercomparison of the cases}

Experiments involving assimilation of satellite and lightning activity information into the simulations (see Table 1), produce significant modifications on the forecasts (see Figs. 9 and 12). Simulated medicanes are deeper in almost all cases for the September 1996 episode and weaker for the October 2003 case. According to the upper-level influences previously discussed, trajectories of medicanes have changed significantly owing to other causes rather than to the 

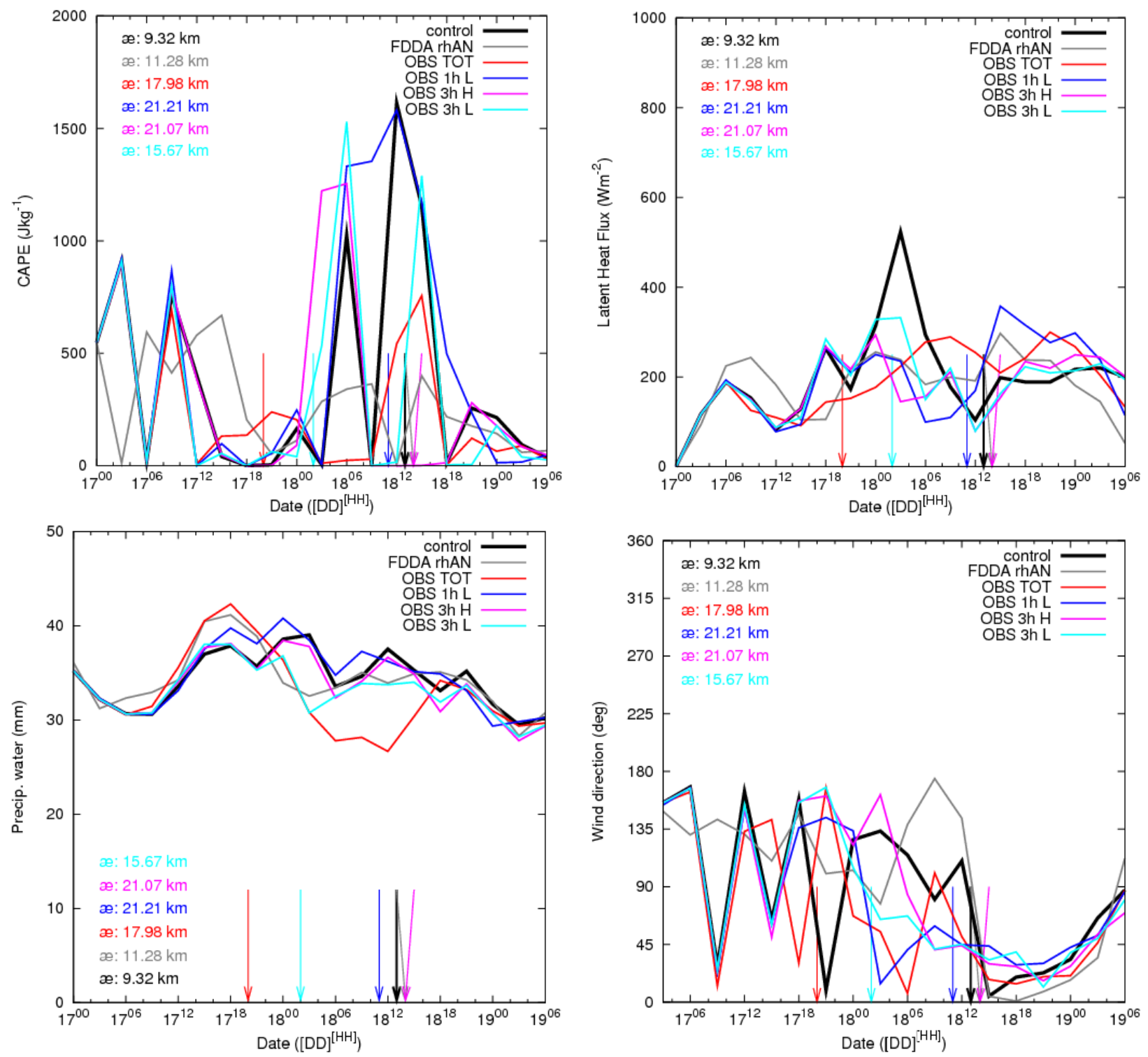

Fig. 13. As in Fig. 10, but for October 2003 medicane at point B. Different scales for CAPE and LHF meteograms than in previous case.

modifications of the upper-level evolutions. In some cases, genesis of simulated medicanes take place at different locations than in the control simulations. Regarding trajectories in general, these slightly improve for September 1996 case and significantly improve for October 2003 medicane, compared to the control ones. The Taylor diagrams show how simulated trajectories for September 1996 medicane are much closer to the satellite observed (lower pseudo-RMSE) than October 2003.

The simulated trajectories, by the whole set of experiments, have similar bias with respect to the satellite-based trajectory (see top right panels in Figs. 11 and 14). It is shown how the satellite-derived information has mainly influenced the localisation in time of the medicane but it has basically left the morphology of the trajectories unchanged.

Different dependence of BIAS dist $_{\text {min }}$ on temporal shift is obtained for each medicane (see bottom left panels in Figs. 11 and 14). The trajectories of September 1996 case do not present a dependence on the temporal shift. In contrast, October 2003 trajectories show a significant improvement of the statistical score with a delay of $18 \mathrm{~h}$, reflecting the strong difference between formation phase of the simulated medicanes and the satellite genesis zone.

There is a case-dependence of the pure correlations results. With obtained results, one can not derive a clear conclusion of the sensitivity of the observation nudging on the temporal and spatial resolution of the data. The September 1996 case exhibits a higher sensitivity to the temporal resolution than to 

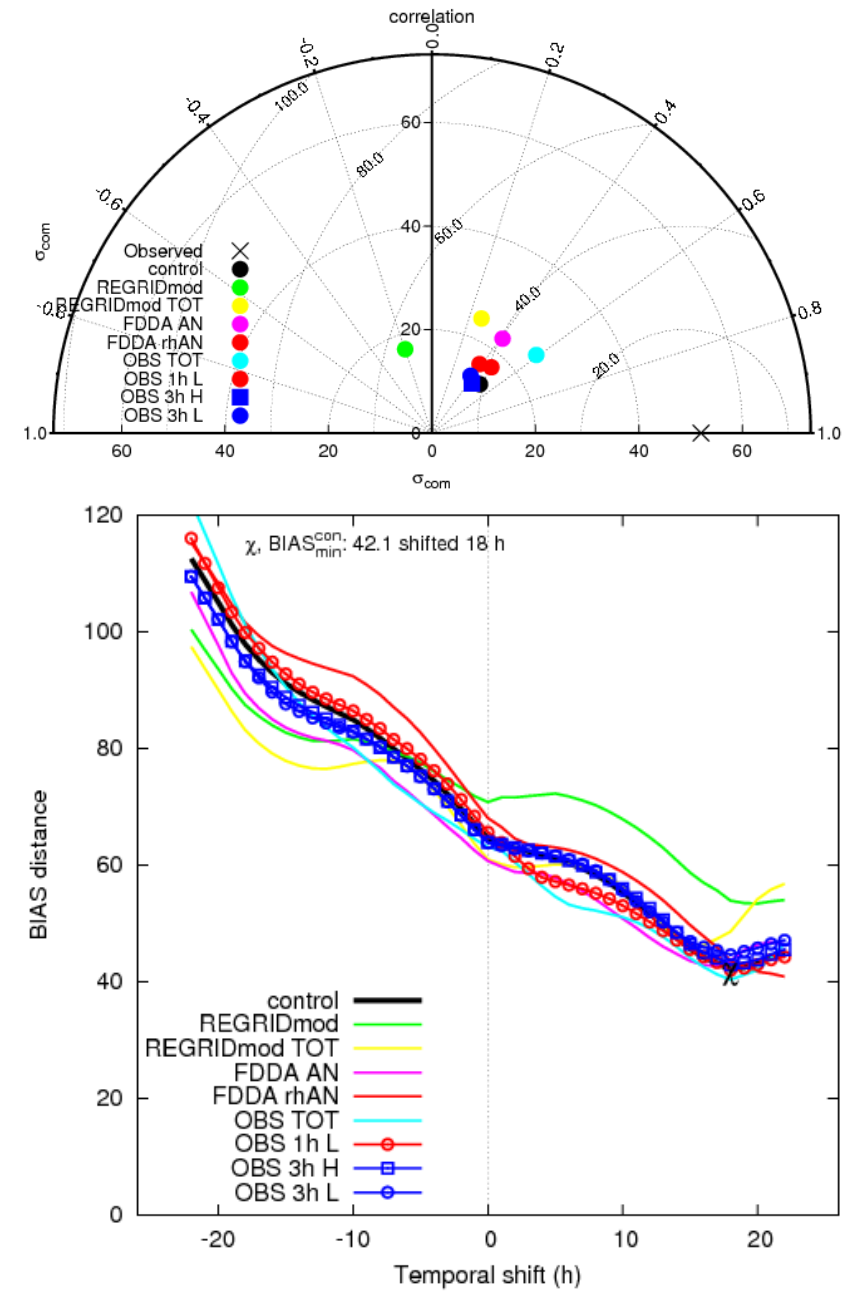

Fig. 14. As in Fig. 11, but for the October 2003 medicane.

the spatial resolution of the assimilated data, while October 2003 is more sensitive to the spatial resolution.

\subsection{Complementary experiments}

In order to provide a wider perspective of the methodology, three more sensitivities are analysed: sensitivity to vertical humidity profile, effect of the satellite/lightning spatial information/coherence into the assimilation, and the role of nudging coefficients.

\subsubsection{Sensitivity to vertical humidity profiles}

In order to study the sensitivity to the vertical saturation profiles, a two more experiments are done with stronger vertical saturation representations. These new sets of experiments (B and C) are performed according to three saturation vertical profiles (see Fig. 15, compared with initial profiles in Fig. 3). In the $C_{B}$ profile corresponding to convective precipitation points of experiment $\mathrm{B}$, saturation is increased in
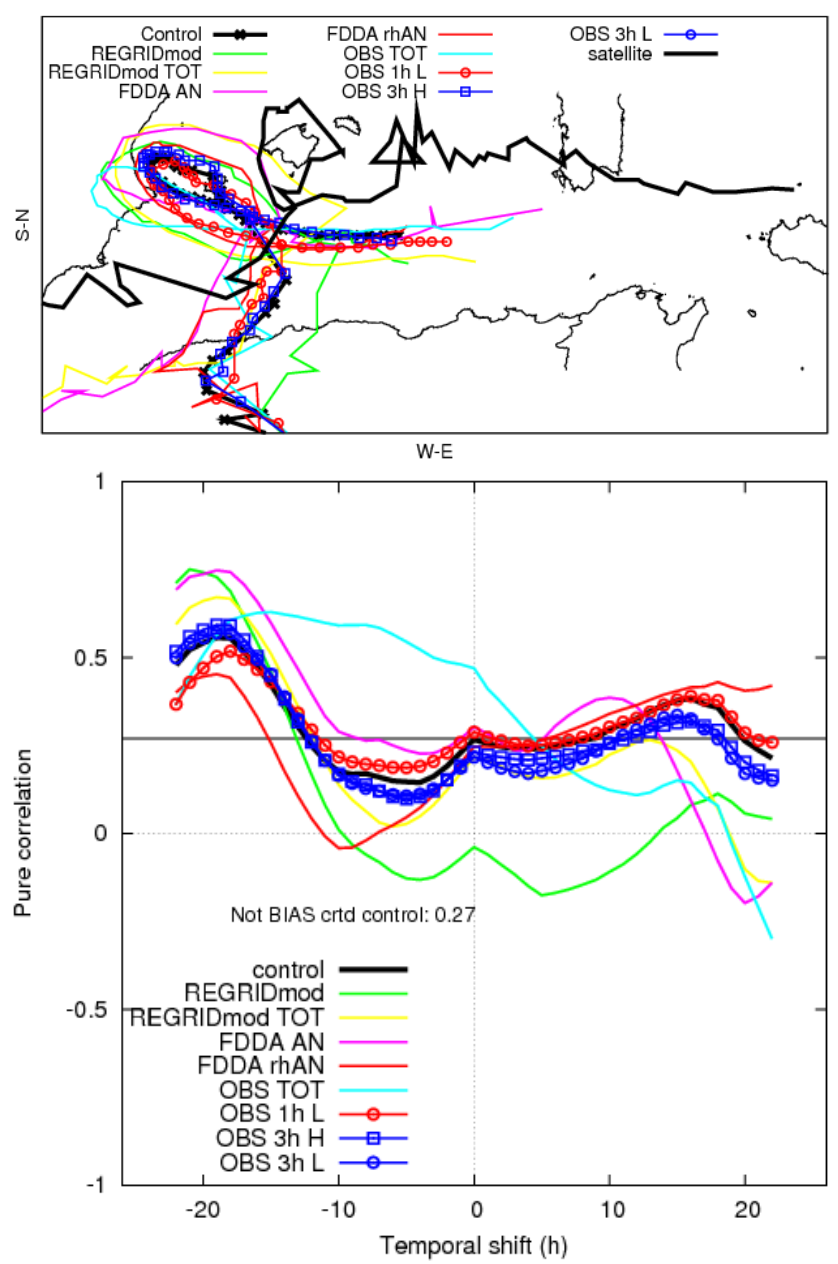

depth at the low-levels (until 0.9 sigma level). $S_{B}$ profile, for stratiform precipitation points in experiment $\mathrm{B}$, the saturation layer is narrower. Profile $C_{C}$ saturates the low and mid-levels, and will be used as a common profile for both stratiform and convective precipitation types (experiment C). These sensitivity tests are applied with the 'OBS TOT' experiment data in both events and are labelled as "OBS pB TOT" and "OBS pC TOT" experiments.

The new vertical profiles produce weaker medicanes in terms of the central sea level pressure (see top panels in Fig. 16), but when a stronger saturation is induced (as it is done with vertical profiles B and C) stronger winds are obtained (middle panels of the figure). Trajectories are improved with respect to the initial experiment "OBS TOT" (OBS pA TOT). It is notorious to see the low impact of saturation at low levels in terms of medicane intensity. It could be expected that larger saturation at low levels (C profile) will produce deeper convection leading to deeper medicanes. The impact on convection is analysed in a following section. 


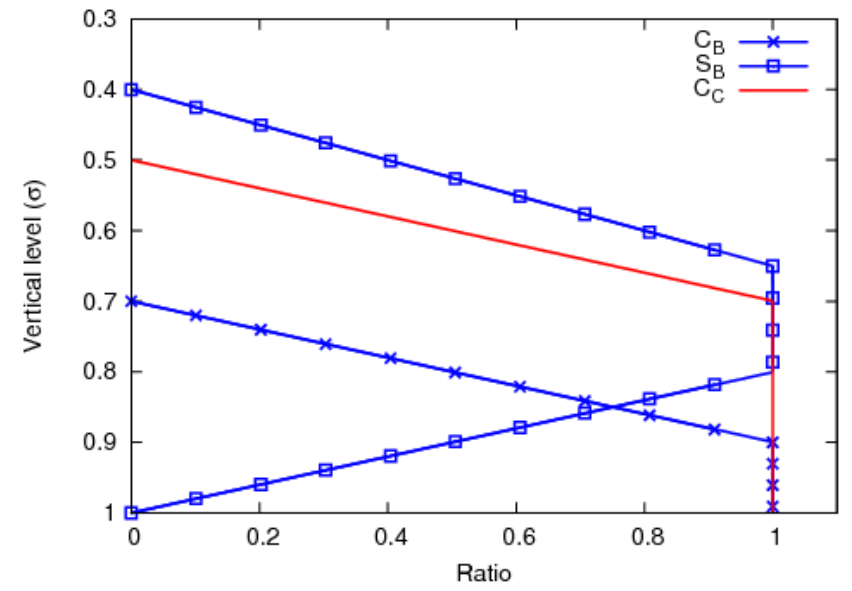

Fig. 15. Vertical saturation profiles. For experiment B, stratiform profile is shown using empty squares and convective profile using crosses.

Table 2. Average during all the period of data assimilation of the proportion of convective $\left(\mathcal{N}_{\text {con }}\right)$ and stratiform $\left(\mathcal{N}_{\text {str }}\right)$ rainy points. Standard deviation $(\sigma)$ of the proportion during the same period.

\begin{tabular}{lcc}
\hline medicane & $<\mathcal{N}_{\text {con }} / \mathcal{N}_{\text {str }}>$ & $\sigma$ \\
\hline 960912 & 0.36 & 0.13 \\
031018 & 0.28 & 0.06 \\
\hline
\end{tabular}

\subsubsection{Sensitivity to satellite/lightning information}

The moisture content plays an important role on precipitation (Romero et al., 1997) and on medicane formation (Homar et al., 2003). Thus, the saturation of grid points according to satellite/lightning information is likely inducing a deepening or enhancement of the convection and from the previous results, generally, stronger medicanes. However, it is not obvious whether this process is linked to the simple increase of the humidity in the domain, or to the spatial coherence of the assimilated field as well. To investigate this aspect, the role of the spatial distribution of the assimilated data will be analysed. Thus, a new experiment is proposed (labelled "OBS pA TOT random"), in which a similar but spatially incoherent amount of precipitation/lightning information is assimilated. Specifically, a random satellite/lightning data set is generated. This random, spatially distributed data preserves the same temporal averaged, standard deviation and ratio between convective and stratiform precipitation pixels as in the observations (see Table 2).

The results of experiment "OBS pA TOT random" reveal lower differences with respect to the control ones, showing the role of the organisation of the information that is assimi-
Table 3. Variations of MM5 standard nudging coefficients.

\begin{tabular}{lcc}
\hline Experiment & $\mathcal{R}_{q}$ & $\sigma_{z}$ \\
\hline standard & $4 \times 10^{-4}$ & 0.001 \\
$G=10^{-3}$ & $1 \times 10^{-3}$ & 0.001 \\
$G=10^{-4}$ & $1 \times 10^{-4}$ & 0.001 \\
$\sigma_{z}=0.005$ & $4 \times 10^{-4}$ & 0.005 \\
\hline
\end{tabular}

lated by the model. This result is more clear in the September 1996 case (bottom left panel in Fig. 16) than in the October 2003 episode (bottom right panel in Fig. 16).

\subsubsection{Sensitivity to nudging coeficients}

It is known the difficulty to determine appropriated values of nudging coefficients (Zou et al., 1992). Here we show, by means of a complementary experiment, the sensitivity of the results to a pair of coefficients. Obviously more substantial tests would be needed to fully analyse this technical issue, but this kind of analysis is beyond the scope of the present one.

Two parameters are analysed: nudging weight of the assimilated field (humidity, $\mathcal{G}_{q}$ ) and obs. nudging radius of influence in the vertical in sigma coordinates $\left(\sigma_{z}\right)$. The sensitivity study consists of reproducing the "OBS pA TOT" experiment with different values for these coefficients with respect to the "standard" values provided by MM5 model. These two values are individually increased/decreased (see Table 3 for respective values). The sensitivity is evaluated in terms of the trajectory, central pressure value and wind intensity of the simulated medicane.

Simulated medicanes, after modifications in observation nudging coefficients, are significantly different than previous ones. Both medicanes become deeper and with stronger winds (see Fig. 17). Variations in medicanes trajectories are larger than variations with different vertical satured profiles.

\subsubsection{Sensitivity of convection}

Different vertical humidity profiles and vertical nudging coefficient $\left(\sigma_{z}\right)$ might exert a significant impact on convection. In this section, we study the impact of these experiments on the convection all over the simulation domain rather than just on medicane characteristics. Convection is analysed by means of quantity and strength of convective cells. This is considered a better indicator of convection itself, rather than taking other derived quantities, such us rain, since rain is a final product of convection. Here, a convective cell is defined as an isolated core of vertical cloud liquid water flux (WCLW) at $700 \mathrm{hPa}$. A convective cell is numerically defined as a local maxima (within a grid box of $7 \times 7$ grid points, $35 \mathrm{~km}^{2}$ area) of WCLW allover the domain of simulation. 

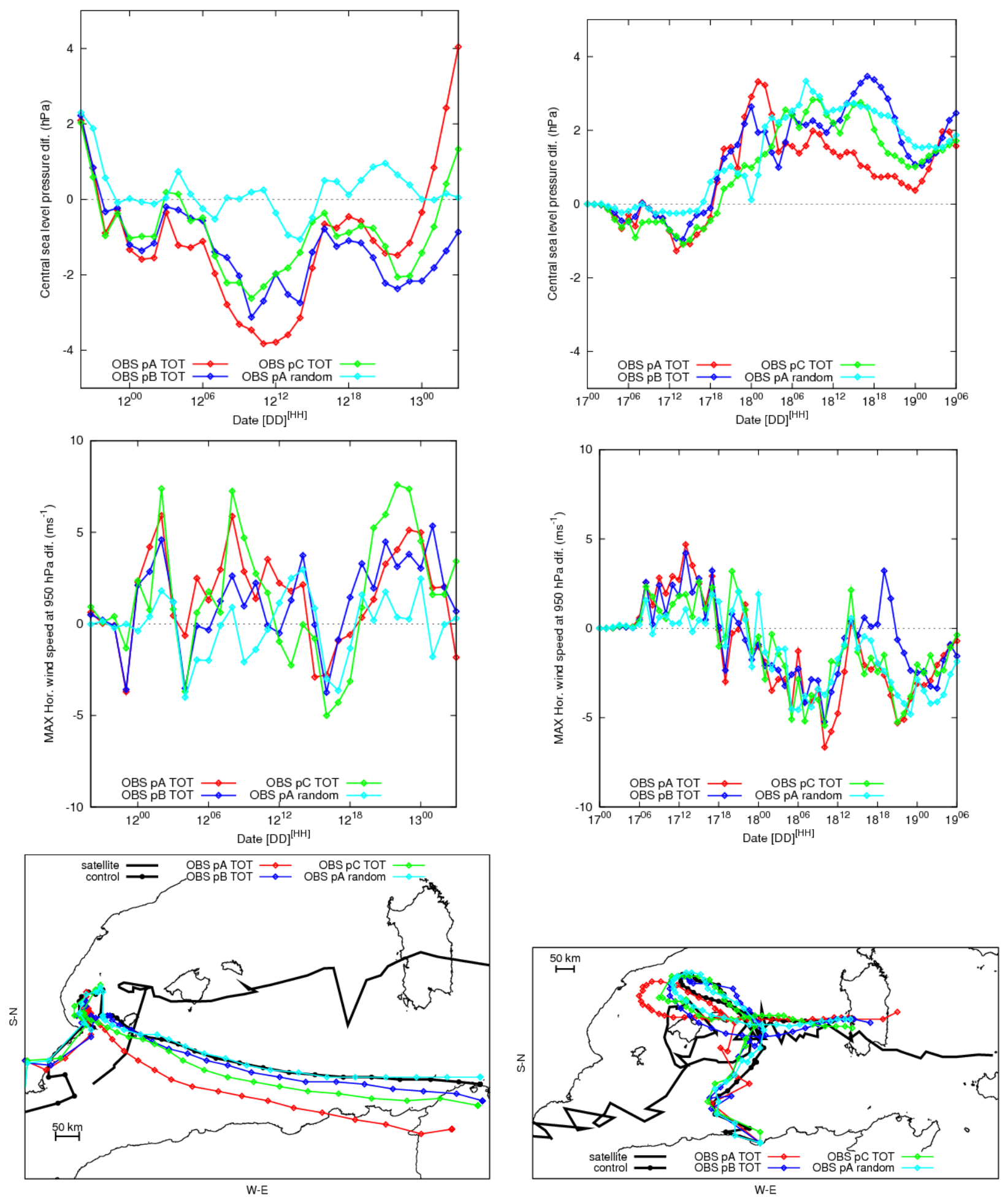

Fig. 16. As in Fig. 9 but for "OBS pA TOT" (experiment), "OBS pB TOT", "OBS pC TOT" and "OBS random" experiments. Left panels: September 1996 medicane. Right panels: October 2003 case. 

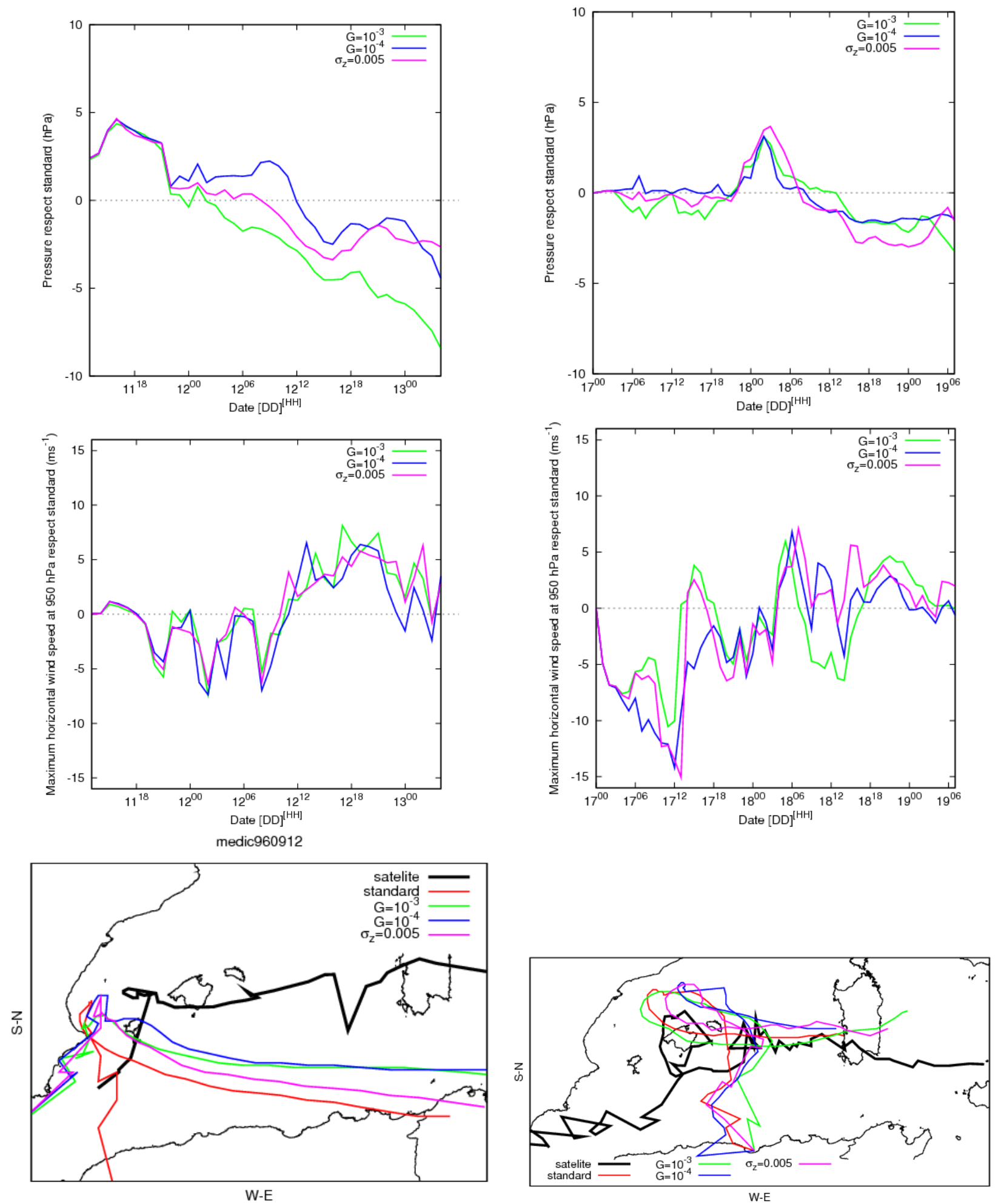

Fig. 17. Evolution of simulated September 1996 medicane (left) and October 2003 (right) with different nudging coefficients. Central pressure evolution (top), maximum horizontal wind speed at $950 \mathrm{hPa}$ within a $100 \mathrm{~km}$ grid box around from the centre of medicane (middle). Medicane trajectory or each experiment in the bottom panels. Standard simulation (red line), $G=10^{-3}$ (green line), $G=10^{-4}$ (blue line), $\sigma_{z}=0.005$ (pink line). 

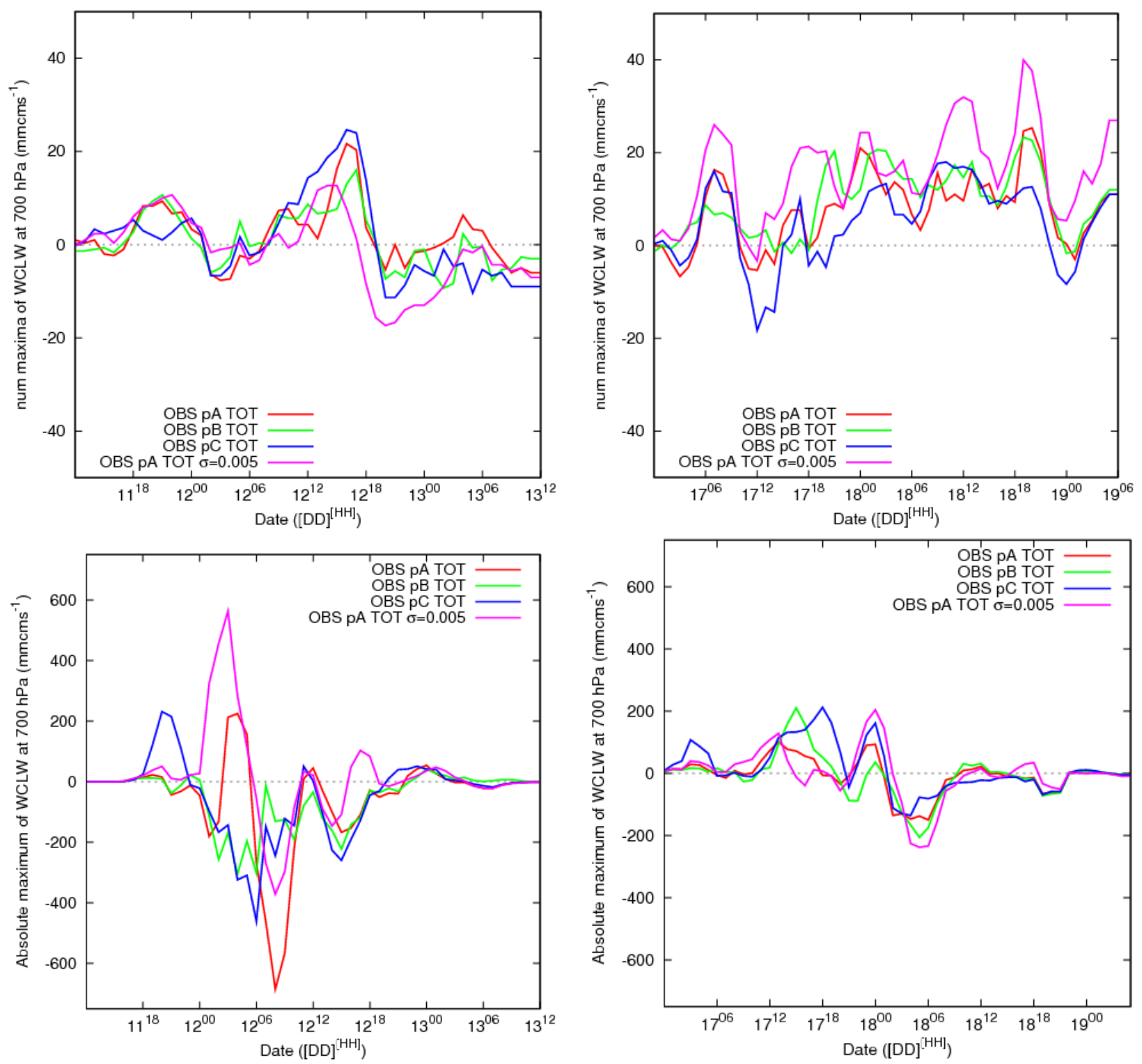

Fig. 18. Temporal evolution of convection (filtered with a moving window of $3 \mathrm{~h}$ ) referred to "OBS pA TOT standard" simulation $\left(\chi_{\operatorname{sim}}-\chi_{\text {con }}\right)$. Number of convective cells (top), absolute maximum (bottom), for September 1996 medicane (left), October 2003 (right). With vertical profile A (red line), profile B (green line), profile C (blue line) and profile A with $\sigma_{z}=0.005$ (pink line).

With respect to control simulations (i.e. without observation nudging), different profiles (A, B, C) and variations of $\sigma_{z}$ coefficient with profile $\mathrm{A}$, have similar impact in both medicanes (see Fig. 18). More convection and stronger cells are generated mainly until simulated medicanes reach their mature state. No significant differences are found between vertical profiles. Simulation with the largest vertical influence of observations $\left(\sigma_{z}=0.005\right)$ present, in general, the largest sensitivity. Results show that humidity variations are not enough to develop stronger convection. One should consider modifying other features involved in convective mode such as thermal profile and wind shear.

\section{Conclusions and further work}

The MM5 model is able to simulate a medicane structure in both September 1996 and October 2003 environments. Simulated tropical-like storms, however, present some differences from the observed path in satellite imagery. Simulated systems evolve more slowly, and for the October 2003 case, the storm is generated in a wrong zone. Medicanes have been revealed as a meteorological feature able to significantly increase surface heat and moisture surface fluxes.

Satellite-derived imagery is a powerful tool to obtain information at high temporal and spatial resolution over maritime 
areas. In this work, images have been used as a method to derive precipitation type, in combination with lightning information which provides a precise way to determine convective grid points. These tools are then used to constrain MM5 vertical humidity profiles to the observed precipitation type. Medicane simulations show a high sensitivity and various responses to the representation of the humidity profile.

Assimilation of the satellite/lightning information presents a case sensitivity, giving opposite results among studied cases. For the September 1996 case, it generates deeper medicanes. In the October 2003 episode, stronger medicanes are obtained, transitorily, only in two experiments. Assimilation of this kind of remote sensing information does not directly imply a significant increase in the thermo-dynamical potential of the atmosphere for medicane enhancement. However, trajectories of simulated systems differ significantly from the observed ones. Other satellite-based information like watervapour channel wind speed estimations could also be retrieved and incorporated into the simulations (Leslie et al., 1998).

Tested statistics to objectively compare different trajectories give clearer results for the September 1996 case than for the October 2003. This can be attributed to the simplicity of the trajectory of the 1996 medicane in comparison to the 2003 case, in which the trajectory presents a loop.

The September 1996 medicane's trajectory is improved when satellite information is used, meanwhile in the October 2003 case it is mainly worsened. Basically, trajectories are only modified in their morphology and genesis zones. No modification of the movement speed of the medicanes is obtained with the assimilation of the satellite/lightning data. A simple modification of the initial and boundary conditions (experiments "REGRIDmod" and "REGRIDmot TOT") is significant enough to generate modifications in the simulated systems. The sensitivity to analyses nudging (exp. FDDA AN and FDDA rhAN) is very strong. In both experiments (with and without humidity correction), medicanes become significantly weaker and have a different impact on their trajectory. Trajectories become better for the September 1996 case and worse in the October 2003 episode. No experiment is able to reduce the temporal shift between observed and simulated medicanes. And a significant improvement of the trajectory is observed for the October 2003 case when a delay of $18 \mathrm{~h}$ is introduced.

Results of FDDA technique for the selected cases, presents a sensitivity on spatial and temporal resolutions of the assimilated data set. It is well-known that the impact of such data with the highest temporal resolution ("OBS TOT" experiments). The modification introduced in both cases is significant, but with a different sign. In the September 1996 case, the medicane is stronger than the control one with the worst trajectory, whereas in the October 2003 case, medicane becomes weaker (except during its formation for two experiments) but with the best trajectory. Pairs of experiments as combination of different temporal ( 1 and $3 \mathrm{~h}$ ) and spatial res- olutions $(3 / 6 \mathrm{~km}$ and $7 / 15 \mathrm{~km})$ have also different behaviour between cases. September 1996 shows a higher dependence on the spatial resolution, whereas there is a larger sensitivity to the temporal resolution in the October 2003 case. This result could be a consequence of the different resolutions of the analyses (from ECMWF) at the corresponding periods of simulation.

The FDDA technique does not show a significant sensitivity on the type of vertical moist saturation profile. A test of different vertical profiles, provides medicane evolutions and trajectories without large differences. The spatial coherence of the assimilated data is case-dependent. For the September 1996 case it has no significant impact, but it presents a light influence on the October 2003 episode.

Significant sensitivity of observation nudging technique on its coefficients has been shown. The complexity to determine appropriated values for the coefficients depending on the type observation to be assimilated is a drawback of the technique. However, the positive impact of the technique for any reasonable configuration of the coefficients has been shown. Observation nudging of satellite and lightning derived saturation vertical profiles shows a stronger sensitivity to the temporal and spatial resolution of the data than sensitivity to the analysed vertical humidity profiles or analysed nudging coefficients.

In order to avoid computational limitations, the MM5 FDDA code should be modified to allow the nudging of higher amount of data independently of computer characteristics. Other modelling issues such as the sensitivity to parametrisation schemes (cumulus, explicit rain) and additional nudging parameters (time-window, radius of influence) should also be carried out in further steps of the study. The sensitivity of the assimilation technique to different temporal and spatial resolutions of the ingested satellite-derived data should also be established and clarified. One defined, satellite based observational nudging could be applied in the initial steps of operational forecasts at national weather services or research centres.

Different statistical coefficients have been presented for an objective intercomparison of simulated and observed trajectories. However, a more robust object-oriented methodology appears to be necessary. This approach should be able to compare more efficiently basic aspects of the cyclones such as: morphology, genesis and evolution zone and speed of evolution.

Acknowledgements. Authors acknowledge the comments of the anonymous reviewers that helped to improve the article. Support from MEDICANES (CGL2008-01271/CLI) and PRECIOSO (CGL2005-03918/CLI) projects and PhD grant BES-2003-0696 (all from the Spanish "Ministerio de Educación y Ciencia") are acknowledged, both projects are partially supported with FEDER founds. Agencia Estatal de Meteorología (AEMET) (spanish metorological service) provided the lighting information, K. Lagouvardos (NOA, Greece) provided the Zeus net lighting information and EUMETSAT the satellite images. Remote Sensing System 
is acknowledged for providing the AMSR and SSMI/I datasets. V. Homar for the suggestions and discussions.

Topical Editor F. D'Andrea thanks K. Lavougardos and another anonymous referee for their help in evaluating this paper.

\section{References}

Businger, S. and Reed, R. J.: Cyclogenesis in cold air masses, Weather Forecast., 4, 133-156, 1989.

Davolio, S. and Buzzi, A.: A nudging scheme for the assimilation of precipitation data into a mesoscale model, Weather Forecast., 19, 855-871, 2004.

Ducrocq, V., Ricard, D., Lafore, J., and Orain, F.: StormScale Numerical Rainfall Prediction for Five Precipitating Events over France: On the Importance of the Initial $\mathrm{Hu}-$ midity Field, Weather Forecast., 17, 1236-1256, doi:10.1175/ 1520-0434(2002)017〈1236:SSNRPF $\rangle$ 2.0.CO;2, 2002.

Emanuel, K. A.: An Air-Sea Interaction Theory for Tropical Cyclones. Part I: Steady-State Maintenance, J. Atmos. Sci., 43, 585-604, 1986.

Emanuel, K. A.: A Statistical Analysis of Tropical Cyclone Intensity, Mon. Weather Rev., 128, 1139-1152, 2000.

Emanuel, K. A.: Genesis and maintenance of "Mediterranean hurricanes", Adv. Geosci., 2, 217-220, 2005, http://www.adv-geosci.net/2/217/2005/.

Fan, X. and Tilley, J. S.: The impact of assimilating satellite-derived humidity on MM5 forecasts, MM5 forecasts. Preprints, 15th Conference on Numerical Weather Prediction, AMS, 12-15 August, San Antonio, TX, pp. 47-50, 2002.

Fita, L., Romero, R., Luque, A., Emanuel, K., and Ramis, C.: Analysis of the environments of seven Mediterranean tropical-like storms using an axisymmetric, nonhydrostatic, cloud resolving model, Nat. Hazards Earth Syst. Sci., 7, 41-56, 2007, http://www.nat-hazards-earth-syst-sci.net/7/41/2007/.

Grell, G. A., Dudhia, J., and Stauffer, D. R.: A description of the Fifth-generation Penn State/NCAR Mesoscale Model (MM5), NCAR Technical Note, NCAR/TN-398+STR, 122pp, 1995.

Homar, V., Romero, R., Stensrud, D., Ramis, C., and Alonso, S.: Numerical diagnosis of a small, quasi-tropical cyclone over the western Mediterranean: Dynamical vs. boundary factors, Q. J. Roy. Meteorol. Soc., 129, 1469-1490, 2003.

Hoskins, B. J., McIntyre, M. E., and Robertson, A. W.: On the use and significance of isentropic potential vorticity maps, Q. J. Roy. Meteorol. Soc., 111, 877-946, 1985.

Janjić, Z. I.: The Step-Mountain Coordinate: Physical Package, Mon. Weather Rev., 118, 1429-1443, 1990.

Janjić, Z. I.: The Step-Mountain Eta Coordinate Model: Further Developments of the Convection, Mon. Weather Rev., 122, 927945, 1994.

Kidd, C., Kniveton, D. R., Todd, M. C., and Bellerby, T. J.: Satellite Rainfall Estimation Using Combined Passive Microwave and Infrared Algorithms, J. Hydrometeorol., 4, 1088-1104, 2003.

Lagouvardos, K. and Kotroni, V.: Improvement of high-resolution weather forecasts through humidity adjustment based on satellite data, Q. J. Roy. Meteorol. Soc., 131, 2695-2712, 2005.

Lagouvardos, K., Kotroni, V., Nickovic, S., Jovic, D., and Kallos, G.: Observations and model simulations of a winter sub-synoptic vortex over the central Mediterranean, Meteorol. Appl., 6, 371383, 1999.
Leslie, L. M., LeMarshall, J. F., Morison, R. P., Spinoso, C., Purser, R. J., Pescod, N., and Seecamp, R.: Improved Hurricane Track Forecasting from the Continuous Assimilation of High Quality Satellite Wind Data, Mon. Weather Rev., 126, 1248-1258, 1998.

Luque, A., Fita, L., Romero, R., and Alonso, S.: Tropical-like Mediterranean Storms: An Analysis from satellite, Proceedings. 2007 Joint EUMETSAT/AMS Conference - Amsterdam, pp. 17, 2007.

Montgomery, M. T. and Farrell, B. F.: Polar Low Dynamics, J. Atmos. Sci., 49, 2484-2505, 1992.

Orlandi, A., Ortolani, A., Meneguzzo, F., Levizzani, V., Torricella, F., and Turk, F. J.: Rainfall assimilation in RAMS by means of the Kuo parameterisation inversion: method and preliminary results, J. Hydrol., 288, 20-35, 2004.

Pytharoulis, I., Craig, G. C., and Ballard, S. P.: The hurricanelike Mediterranean cyclone of January 1995, Meteorol. Appl., 7, 261-279, 2000.

Rasmussen, E. and Zick, C.: A subsynoptic vortex over the Mediterranean with some resemblance to polar lows, Tellus A, 39, 408425, 1987.

Reed, R. J., Kuo, Y.-H., Albright, M. D., Gao, K., Gua, Y.-R., and Huang, W.: Analysis and modeling of a tropical-like cyclone in the Mediterranean Sea, Meteorol. Atmos. Phys., 76, 183-202, 2001.

Roberts, R. D. and Rutledge, S.: Nowcasting Storm Initiation and Growth Using GOES-8 and WSR-88D Data, Weather Forecast., 18, 562-584, 2003.

Romero, R., Ramis, C., and Alonso, S.: Numerical simulation of an extreme rainfall event in Catalonia: Role of orography and evaporation from the sea, Q. J. Roy. Meteorol. Soc., 123, 537$559,1997$.

Stauffer, D. R. and Seaman, N. L.: Use of Four-Dimensional Data Assimilation in a Limited-Area Mesoscale Model. Part I: Experiments with Synoptic-Scale Data, Mon. Weather Rev., 118, 1250-1277, doi:10.1175/1520-0493(1990)118〈1250:UOFDDA〉 2.0.CO;2, 1990.

Taylor, K. E.: Summarizing multiple aspects of model performance in a single diagram, J. Geophys. Res., 106, 7183-7192, 2001.

Turk, F. J., Rohaly, G., Hawkins, J. D., Smith, E. A., Grose, A., Marzano, F. S., Mugnai, A., and Levizzani, V.: Analysis and assimilation of rainfall from blended SSMI, TRMM and geostationary satellite data, 10th AMS Conference on Satellite Meteorology and Oceanography, Long Beach CA, 15 January 2000, pp. 66-69, 2000.

WMO: FM 94XIII Ext. BUFR Binary universal form for the representation of meteorological data, http: //www.wmo.int/pages/prog/www/WMOCodes/Operational/ BUFR/FM94REG-11-2007.pdf, pp. 1-12, 2007.

Zhang, D., Liu, Y., and Yau, M.: A Multiscale Numerical Study of Hurricane Andrew (1992). Part V: Inner-Core Thermodynamics, Mon. Weather Rev., 130, 2745-2763, 2002.

Zou, X. and Xiao, Q.: Studies on the Initialization and Simulation of a Mature Hurricane Using a Variational Bogus Data Assimilation Scheme, J. Atmos. Sci., 57, 836-860, 1999.

Zou, X., M.Navon, J., and Ledimet, F. X.: An optimal nudging data assimilation scheme using parameter estimation, Q. J. Roy. Meteorol. Soc., 118, 1163-1186, doi:10.1002/qj.49711850808, 1992. 